\title{
$\beta$-Hydrogen Elimination Reactions of Nickel and Palladium Methoxides Stabilized by PCP Pincer Ligands
}

\author{
Luis M. Martínez-Prieto, Elena Ávila, Pilar Palma, Eleuterio Álvarez and Juan Cámpora*[a]
}

\begin{abstract}
Nickel and palladium methoxides [( $\left.\left.{ }^{\mathrm{iPr}} \mathrm{PCP}\right) \mathrm{M}-\mathrm{OMe}\right]$, containing the ${ }^{\mathrm{IPr}} \mathrm{PCP}$ pincer ligand, decompose upon heating giving rise to products of different kind. The palladium derivative cleanly yields the dimeric $\mathrm{Pd}(0)$ complex $\left[\mathrm{Pd}\left(\mu-{ }^{\mathrm{iPr}} \mathrm{PCHP}\right)\right]_{2}\left({ }^{\mathrm{iPr}} \mathrm{PCHP}=2,6-\right.$ bis(diisopropylphosphinomethyl)phenyl) and formaldehyde. In contrast, decomposition of $\left[\left({ }^{\mathrm{iPr}} \mathrm{PCP}\right) \mathrm{Ni}-\mathrm{OMe}\right]$ affords polynuclear carbonyl-phosphine complexes. Both decomposition processes are initiated by $\beta$-hydrogen elimination (BHE), but the resulting hydrides $\left[\left({ }^{\mathrm{Pr}} \mathrm{PCP}\right) \mathrm{M}-\mathrm{H}\right]$ undergo divergent reaction sequences ultimately leading to the irreversible breakdown of the pincer units. Whilst the $\mathrm{Pd}$ hydride spontaneously experiences reductive $\mathrm{C}-\mathrm{H}$ coupling, the decay of its $\mathrm{Ni}$ analogue is brought about by its reaction with formaldehyde released in the BHE step. Kinetic measurements showed that the BHE reaction is reversible and less favorable for $\mathrm{Ni}$ than for Pd both for kinetic and thermodynamic reasons. DFT calculations confirmed the main conclusions of the kinetic studies, and provided further insight into the mechanisms of the decomposition reactions.
\end{abstract}

\section{Introduction}

Over the past forty years, tridentate anionic pincer ligands have become a privileged platform for the development of organometallic chemistry and homogeneous catalysis. ${ }^{[1]}$ Far from limiting the chemistry on the coordination sphere of transition metal complexes, rigid pincer scaffolds enable a rich and often unexpected reactivity. They also facilitate the direct observation of processes and the detection of intermediates, in a manner that would be difficult or impossible in less tightly assembled systems. In catalysis, ${ }^{[2]}$ the inexhaustible diversity of pincer ligands facilitates the fine-tuning of the metal environment, enhancing the stability of their complexes as homogeneous systems or regulating their ability to act as controlled dispensers of nanoparticles. In addition, beyond their role as stabilizing or modulator ligands, pincers often provide true examples of cooperative metal-ligand behaviour. ${ }^{[3]}$

The planar configuration of pincer ligands make them especially well suited for the stabilization of $\mathrm{Pd}(\mathrm{II}), \mathrm{Ni}(\mathrm{II})$ and other 16-e metal centres, therefore the number of applications of these complexes is increasing continuously. ${ }^{[4]}$ In recent years our group has devoted attention to the synthesis and the chemical reactivity of nickel and palladium hydroxide and alkoxide complexes, with the purpose of developing applications

[a] Dr. L. M. Martínez-Prieto, Dr. P. Palma, Dr. E. Álvarez, Prof. Dr. J. Cámpora

Instituto de Investigaciones Químicas.

CSIC - Universidad de Sevilla

c/ Américo Vespucio, 49, 41092 Sevilla, Spain

E-mail: campora@iiq.csic.es

Supporting information for this article is given via a link at the end of the document. in homogeneous catalysis. ${ }^{[5]}$ In particular, we focused on the strongly donor pincer ligand 2,6-bis(diisopropylphosphino)methylphenyl ( $\left.{ }^{\mathrm{Pr}} \mathrm{PCP}\right)$ due to its excellent balance between an adequate steric shielding of the metal centre and its ability to promote nucleophilic and/or basic reactivity on the alkoxide or hydroxide ligands. ${ }^{[6]}$

We recently reported that the palladium hydroxide complex $\left[\left({ }^{\mathrm{iPr}} \mathrm{PCP}\right) \mathrm{Pd}-\mathrm{OH}\right]$ is readily reduced by methanol or isopropanol to a well-defined $\operatorname{Pd}(0)$ species through a sequence of reactions involving the decomposition of the intermediate methoxide or isopropoxide complexes [ $\left.\left.{ }^{\mathrm{iPr}} \mathrm{PCP}\right) \mathrm{Pd}-\mathrm{OR}\right]\left(\mathrm{R}=\mathrm{Me},{ }^{\mathrm{i}} \mathrm{Pr}\right)$ by $\beta$ hydrogen elimination (BHE) ${ }^{[7]}$ This reactivity pattern could be involved in many catalytic reactions in which pincer complexes act as precursors for reduced species or metal nanoparticles, which are the true active catalysts. ${ }^{[8]}$ However, BHE also plays an essential role in reactions that are actively catalyzed by pincer complexes, such as alcohol dehydrogenation, oxidation or coupling with imines or amines. These applications typically involve pincer complexes of $\operatorname{~r~}^{[9]}$ or $\mathrm{Ru}^{[10]}$ but much more rarely of $\mathrm{Pd}$ or any of its group 10 congeners. ${ }^{[11]}$ The apparent lack of reactivity of the latter could arise from a generalized reluctance of square planar 16 -electron complexes, ${ }^{[12]}$ and in particular of the corresponding alkoxo derivatives ${ }^{[13]}$ to undergo $\mathrm{BHE}$ processes when the metal centre is locked into a rigid pincer scaffold. In part, the stability of such pincer alkoxides might have a thermodynamic origin, as both theoretical ${ }^{[13 a]}$ and experimental work $^{[14]}$ have shown that at least some types of BHE eliminations of pincer-chelated late transition metal complexes might be disfavoured with regard to their reversal (e. g., insertion of aldehyde or ketone into an $\mathrm{M}-\mathrm{H}$ bond). However, kinetics could also be determinant for the stability of 16-e alkoxides with pincer ligands. A general condition for all types of BHE is the presence of a coordination vacancy on the metal centre ${ }^{[15]}$ and mechanistic investigations revealed that BHE in Ir alkoxides do in fact require pre-dissociation of a ligand cis to the alkoxo group. ${ }^{[16]}$ Although early mechanistic studies on the decomposition of platinum(II) alkoxo complexes concluded the required metal- $\beta \mathrm{H}$ interaction could involve the free axial position, ${ }^{[17]}$ ligand dissociation has often been considered to be a requirement for $\mathrm{BHE}$ in alkoxide intermediates in $\mathrm{Pd}$-catalyzed alcohol oxidation reactions. ${ }^{[18]}$ Such a condition can be difficult or impossible to fulfil for pincer complexes.

When the lack of dissociable ligands prevents the generation of a coordination vacancy, a mechanistic detour may allow BHE to proceed formally. ${ }^{[19]}$ One such alternative pathways involves dissociation of the alkoxide ligand itself, followed by backside abstraction of an $\mathrm{H}$ atom from the alkoxide anion by the cationic metal fragment, and therefore it is usually referred as dissociative $\beta$-hydrogen abstraction mechanism. ${ }^{[19 b, c]}$ It has been suggested that this might provide an accessible route for the decomposition of alkoxo-palladium complexes stabilized by rigid pincer ligands. ${ }^{[13 b, 20]}$ However, this type of mechanism requires very specific conditions to become operative (for example, the presence of free alcohol appears to be essential to 
promote alkoxide dissociation) and would be less likely for $\mathrm{Ni}(\mathrm{II})$, as this is not so prone as $\mathrm{Pd}(\mathrm{II})$ to $\mathrm{C}-\mathrm{H}$ activation. Noteworthy, examples of the decomposition of well-characterized nickel alkoxides are scarce in the literature, ${ }^{[5 \mathrm{~d}, 21]}$ and virtually none refer to rigidly ligated pincer ligands. Agapie has recently described the decomposition of a nickel methoxide stabilized by $m$-terphenyl-based PCP ligand that allows for a considerable conformational flexibility. ${ }^{[21 a]}$

Our interest on the chemistry of monomeric $\mathrm{Ni}$ and $\mathrm{Pd}$ alkoxide complexes led us to examine the kinetics of the decomposition of the palladium methoxide complex $\left[\left({ }^{\mathrm{Pr}} \mathrm{PCP}\right) \mathrm{Pd}-\right.$ $\mathrm{OMe}]$, and to extend this work to its nickel analogue, $\left[\left({ }^{\mathrm{iPr}} \mathrm{PCP}\right) \mathrm{Ni}-\right.$ OMe]. In the light of these studies, we have modelled the mechanisms of these processes using DFT techniques. Herein we report the results of this work.

\section{Results and Discussion}

\section{Thermal decomposition of $\mathrm{Ni}$ and $\mathrm{Pd}$ methoxide complexes.}

As anticipated from our previous studies on the decomposition of the palladium hydroxide $\left[\left({ }^{i \mathrm{Pr}} \mathrm{PCP}\right) \mathrm{Pd}-\mathrm{OH}\right]{ }^{[7]}$ authentic samples of $\left.{ }^{\mathrm{iPr}}(\mathrm{PCP}) \mathrm{Pd}-\mathrm{OMe}\right]$ exhibit the same behaviour as the hydroxide when heated in methanol solution, decaying into the dimer $\left[\mathrm{Pd}\left(\mu-{ }^{\mathrm{iPr}} \mathrm{PCHP}\right)\right]_{2}$ (Scheme 1). ${ }^{31} \mathrm{P}\left\{{ }^{1} \mathrm{H}\right\}$ NMR monitoring of this transformation reveals the gradual appearance of the characteristic low frequency signal of the dimeric $\mathrm{Pd}(0)$ product $(\delta 42.9 \mathrm{ppm})$, until its concentration reaches a certain threshold above which it precipitates quantitatively. Beyond this point, the resonance of the $\operatorname{Pd}(0)$ product disappears from the spectrum but the intensity of the starting methoxide ( $\delta 59.4 \mathrm{ppm})$ continues to decrease with regard to that of $\mathrm{O}=\mathrm{PPh}_{3}$ added as internal standard.

$\left[\mathrm{Pd}\left(\mu-{ }^{\mathrm{iPr}} \mathrm{PCHP}\right)\right]_{2}$ is soluble in benzene, consequently when the decomposition of $\left.{ }^{\mathrm{iPr}}(\mathrm{PCP}) \mathrm{Pd}-\mathrm{OMe}\right]$ is carried out in this solvent, the solution remains homogenous throughout the whole experiment. Figure 1 (left side) shows the ${ }^{31} \mathrm{P}\left\{{ }^{1} \mathrm{H}\right\}$ spectrum of a sample of $\left[{ }^{i P r}(P C P) P d-O M e\right]$ before $(A)$ and after $(B)$ heating at $65^{\circ} \mathrm{C}$ for $6 \mathrm{~h}$. In the latter, the signals of the starting material and the $\operatorname{Pd}(0)$ product can be observed together with an intense resonance of the hydride $\left[\left({ }^{\mathrm{iPr}} \mathrm{PCP}\right) \mathrm{Pd}-\mathrm{H}\right]$ at $\delta 73.0 \mathrm{ppm}$. This indicates that the hydride is much more stable in benzene than in methanol, where its characteristic signature can hardly be observed as a faint feature in the ${ }^{31} \mathrm{P}$ spectrum. Separate measurements showed that while the hydride decomposes very fast in methanol even at room temperature, it is stable in benzene up to $50{ }^{\circ} \mathrm{C}$, and even above this temperature its decomposition to $\left[\mathrm{Pd}\left(\mu-{ }^{\mathrm{iPr}} \mathrm{PCHP}\right)\right]_{2}$ is slow. At $100{ }^{\circ} \mathrm{C}$, the halflive of a hydride sample in $C_{6} D_{6}$ is ca. $4 \mathrm{~h}\left(\Delta \mathrm{G}^{\ddagger} \approx 29 \mathrm{kcal} \cdot \mathrm{mol}^{-1}\right)$. Addition of small amounts of methanol significantly decreases the stability of the solutions of $\left[\left({ }^{i P r} \mathrm{PCP}\right) \mathrm{Pd}-\mathrm{H}\right]$ in $\mathrm{C}_{6} \mathrm{D}_{6}$. For example, addition of 1 equiv of methanol to a $0.05 \mathrm{M}$ solution of $\left[\left({ }^{\mathrm{Pr} P C P}\right) \mathrm{Pd}-\mathrm{H}\right]$ causes it to decompose at $50^{\circ} \mathrm{C}$ with $\mathrm{t}_{1 / 2}=12.8 \mathrm{~h}$. Since $\left[{ }^{\mathrm{iPr}}(\mathrm{PCP}) \mathrm{Pd}-\mathrm{OMe}\right]$ is extremely sensitive to moisture and it usually contains small amounts of free methanol, it cannot be excluded that traces of the alcohol could help the decomposition of the hydride even when the thermolysis reaction is carried out in benzene.

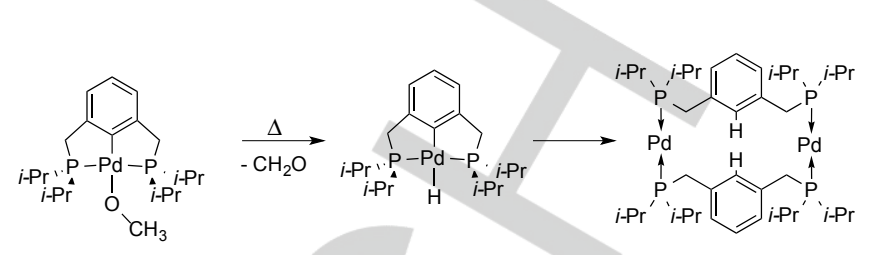

Scheme 1. Decomposition of the palladium complex $\left[\left({ }^{(\mathrm{Pr}} \mathrm{PCP}\right) \mathrm{Pd}-\mathrm{OMe}\right]$

$\left[\left({ }^{\mathrm{iPr}} \mathrm{PCP}\right) \mathrm{Ni}-\mathrm{OH}\right]$ solutions in methanol contain equilibrium mixtures of the hydroxide and the methoxide. In contrast with those of its $\mathrm{Pd}$ analogue, these solutions are stable well above the room temperature. However, the behaviour of the methoxide $\left[\left({ }^{\mathrm{iPr}} \mathrm{PCP}\right) \mathrm{Ni}-\mathrm{OMe}\right]$ in $\mathrm{C}_{6} \mathrm{D}_{6}$ resembles that of its palladium counterpart. At $50^{\circ} \mathrm{C}$ it also decomposes affording selectively the corresponding hydride, albeit at appreciably slower pace. As observed in the Pd system, raising the temperature causes the formation of new P-containing products (Eq. 1). Typical ${ }^{31} \mathrm{P}\left\{{ }^{1} \mathrm{H}\right\}$ spectra corresponding to the thermolysis of $\left[\left({ }^{\mathrm{iPr}} \mathrm{PCP}\right) \mathrm{Ni}-\mathrm{OMe}\right]$ at $90{ }^{\circ} \mathrm{C}$ are shown in Figure 1 (right side: $\mathrm{C}$, initial spectrum; $\mathrm{D}$, after ca. 1 day). As can be seen, in addition to the [ $\left.\left.{ }^{\mathrm{PPr} P C P}\right) \mathrm{Ni}-\mathrm{H}\right]$ signal at $76.9 \mathrm{ppm}$, some other signals can be observed corresponding to ${ }^{\mathrm{IPr}} \mathrm{PCHP}$ ( $\left.\delta 9.1 \mathrm{ppm}\right)$, and to some other products in the proximity of $40 \mathrm{ppm}$ (inset). Among the latter there is a particularly intense singlet at $\delta 38.6 \mathrm{ppm}$ that becomes the dominant spectral feature at longer reaction times. This signal is shifted to low frequency with regard to what is typical for $\mathrm{Ni}$ complexes containing the intact cyclometallated pincer moiety (usually $>50 \mathrm{ppm}$ ), which is reminiscent of the $\operatorname{Pd}(0)$ complex $\left[\mathrm{Pd}\left(\mu-{ }^{\mathrm{PPr}} \mathrm{PCHP}\right]_{2}(42.9 \mathrm{ppm})\right.$. This suggests that the $\delta$ $38.6 \mathrm{ppm}$ product could be a related $\mathrm{Ni}(0)$ species, perhaps arising from the thermal decomposition of $\left[\left({ }^{\mathrm{Pr}} \mathrm{PCP}\right) \mathrm{Ni}-\mathrm{H}\right]$. In order to check this hypothesis, we investigated the thermal

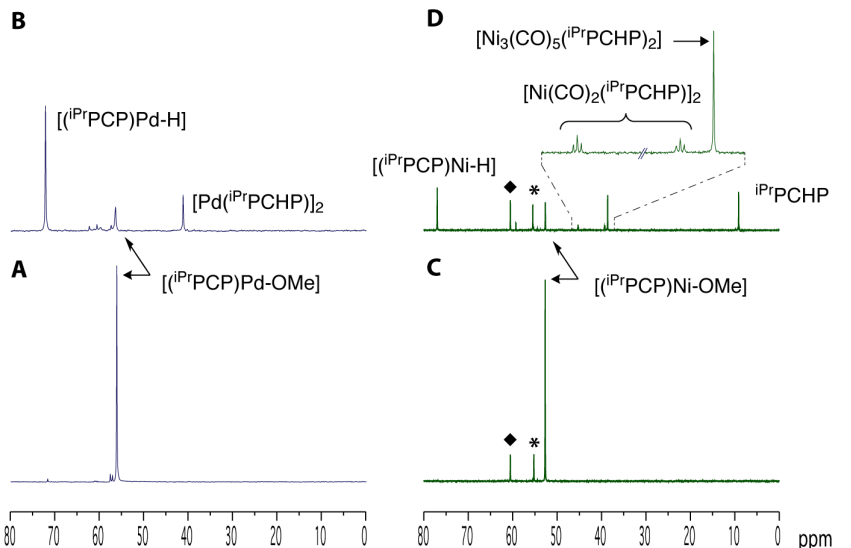

Figure 1. Representative ${ }^{31} \mathrm{P}\left\{{ }^{1} \mathrm{H}\right\}$ spectra corresponding to the decomposition of $\left.\left[{ }^{\circ{ }^{\mathrm{Pr}} \mathrm{PCP}}\right) \mathrm{M}-\mathrm{OMe}\right]\left(\mathrm{M}=\mathrm{Pd}\right.$ (left) and $\mathrm{Ni}$ (right) in $\mathrm{C}_{6} \mathrm{D}_{6} . \mathrm{A}$ and $\mathrm{C}$, initial spectra. $\mathrm{C} ; \mathrm{M}=\mathrm{Pd}$, after $6 \mathrm{~h}$ at $65^{\circ} \mathrm{C} ; \mathrm{D}, \mathrm{M}=\mathrm{Ni}$, after $26 \mathrm{~h}$ at $90^{\circ} \mathrm{C}$. Signals marked $*$ and correspond to small amounts of the hydroxide and bromide complexes, respectively. 
behaviour of the latter compound.

$\left.\left.{ }^{\mathrm{iPr}} \mathrm{PCP}\right) \mathrm{Ni}-\mathrm{H}\right]$ is much more stable than its $\mathrm{Pd}$ counterpart, and resists prolonged heating in $\mathrm{C}_{6} \mathrm{D}_{6}$. After heating at $100{ }^{\circ} \mathrm{C}$ for $48 \mathrm{~h}$ its NMR spectra only began to evidence some degradation, but the ${ }^{31} \mathrm{P}$ resonance at $\delta 38.6 \mathrm{ppm}$ was not observed. However, it is conceivable that, as observed in the $\mathrm{Pd}$ system, the decomposition of the Ni hydride could be facilitated by small amounts of $\mathrm{MeOH}$ that usually exist in the samples of the methoxide. To clarify this point, we investigated the influence of methanol on the thermal stability of $\left[\left({ }^{\mathrm{PPr}} \mathrm{PCP}\right) \mathrm{Ni}-\mathrm{H}\right]$. Far for promoting the formation of a $\mathrm{Ni}(0)$ species, methanol slowly reacts with the hydride to afford methoxide together with $\mathrm{H}_{2}$, according to Eq 2. ${ }^{31} \mathrm{P}\left\{{ }^{1} \mathrm{H}\right\}$ monitoring showed the formation of a small amount of [( $\left.\left.{ }^{\mathrm{iPr} P C P}\right) \mathrm{Ni}-\mathrm{OMe}\right]($ approx. $10 \%)$ together with very minor amounts of some unknown species when the hydride was heated in $\mathrm{C}_{6} \mathrm{D}_{6}$ at $60^{\circ} \mathrm{C}$ in the presence of 2 equivalents of $\mathrm{MeOH}$ for $51 \mathrm{~h}$. Complete conversion was observed when a solution of $\left[\left({ }^{\mathrm{iPr}} \mathrm{PCP}\right) \mathrm{Ni}-\mathrm{H}\right]$ in a $6: 1 \quad \mathrm{C}_{6} \mathrm{D}_{6} /$ methanol mixture was heated for $5 \mathrm{~h}$ at the same temperature. A characteristic resonance at $\delta 4.51 \mathrm{ppm}$ in the ${ }^{1} \mathrm{H}$ spectrum confirmed the formation of $\mathrm{H}_{2}$. These experiments demonstrate that, in contrast with the $\mathrm{Pd}$ system, the final decay of the $\mathrm{Ni}$ hydride neither occurs spontaneously, nor induced by free alcohol. Remarkably, the reaction of the nickel hydride with methanol is the reversal of alkoxide hydrogenolysis, that Goldberg has reported recently for $\left[\left({ }^{\mathrm{BB}} \mathrm{PCP}\right) \mathrm{Pd}-\mathrm{OR}\right]$ complexes. ${ }^{[20]}$ Note that the combination BHE of the methoxide ( $\mathrm{Eq} 1$ ), and the reaction of the hydride with methanol (Eq 2) would lead to a catalytic cycle for the dehydrogenation of methanol ${ }^{[22]}$ but, in practice, the competing decay of the methoxide complex prevents the progress of such a catalytic process to a significant degree.

$$
\begin{gathered}
{\left[\left({ }^{\text {PPrPCP }}\right) \mathrm{Ni}-\mathrm{OMe}\right] \stackrel{>50^{\circ} \mathrm{C}}{\longrightarrow}\left[\left({ }^{\text {PPrPCP }}\right) \mathrm{Ni}-\mathrm{H}\right]+\mathrm{CH}_{2} \mathrm{O}+\ldots} \\
{\left[\left({ }^{\text {PPrPCP }}\right) \mathrm{Ni}-\mathrm{H}\right]+\mathrm{MeOH} \stackrel{60{ }^{\circ} \mathrm{C}}{\longrightarrow}\left[\left({ }^{\text {PPrPCP }}\right) \mathrm{Ni}-\mathrm{OMe}\right]+\mathrm{H}_{2}}
\end{gathered}
$$

Reasoning that the properties of the species responsible for the ${ }^{31} \mathrm{P} \delta 38.6 \mathrm{ppm}$ signal could be similar to those of the $\mathrm{Pd}(0)$ dimer, and being the latter insoluble in methanol, we used this solvent to remove all other components in a mixture generated in the decomposition of $\left[\left({ }^{\mathrm{iPr}} \mathrm{PCP}\right) \mathrm{Ni}-\mathrm{OMe}\right]$ in toluene at $100{ }^{\circ} \mathrm{C}$. The residue left after extraction with methanol was recrystallized from a toluene/methanol mixture. A dark red crystalline material was obtained, from which a well-shaped crystal was selected for $\mathrm{X}$-ray analysis. The crystal structure (Figure 2) corresponds to a dimeric carbonyl complex of composition $\left[\mathrm{Ni}(\mathrm{CO})_{2}\left(\mu{ }^{\mathrm{iPr}} \mathrm{PCHP}\right)\right]_{2}$. Selected bond distances and angles are shown on Table 1. As in the case of $\left[\mathrm{Pd}\left(\mu-{ }^{\mathrm{iPr}} \mathrm{PCHP}\right)\right]_{2}$, both metal atoms are bridged by ${ }^{\mathrm{iPr}} \mathrm{PCHP}$ diphosphine units, but here the $\mathrm{Ni}$ centres have approximately tetrahedral geometries configured by two $\mathrm{P}$ donors and two $\mathrm{CO}$ ligands. The molecule is not symmetrical, as in one of the metal fragments (Ni1) the $\mathrm{CO}$ ligands points outwards from the $\mathrm{Ni}_{2} \mathrm{P}_{2}$ array, and inwards in the other (Ni2). Bond lengths and angles are alike in both centres, and resemble those measured in mononuclear complexes of the type
$\left[\mathrm{Ni}(\mathrm{CO})_{2}\left(\mathrm{PR}_{3}\right)_{2}\right]$. The only significant deviation is found in the P2Ni2-P4 angle $\left(124.72(7)^{\circ}\right)$ which is significantly wider than the tetrahedral angle, while P1-Ni1-P3, 109.56(6) ${ }^{\circ}$ can be considered normal. This might reflect some degree of structural stress in the Ni2 centre.

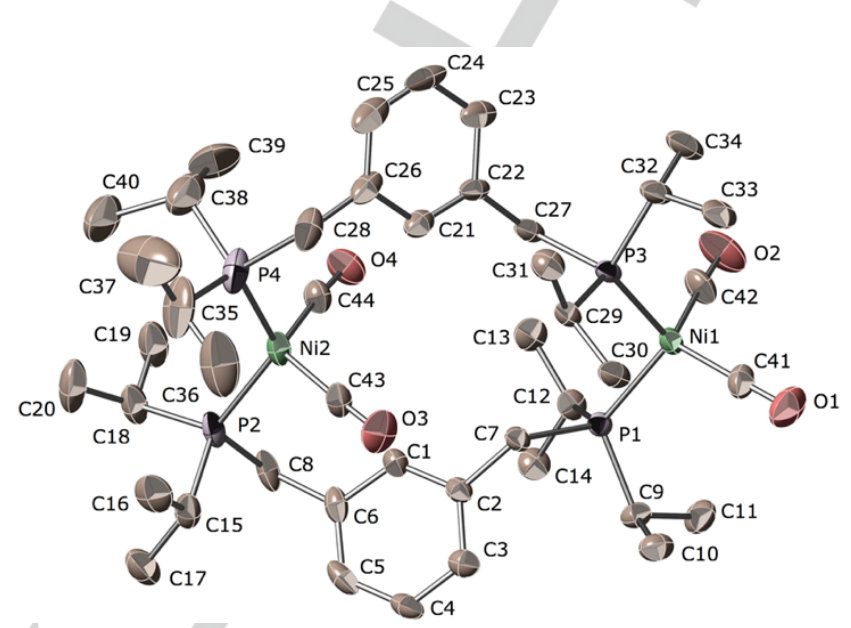

Figure 2. ORTEP plot with $40 \%$ probability ellipsoids of the crystal structure of $\left[\mathrm{Ni}(\mu-\mathrm{CO})_{2}\left(\mu-{ }^{\mathrm{Pr}} \mathrm{PCHP}\right)\right]_{2}$

\begin{tabular}{|c|c|c|c|}
\hline \multicolumn{4}{|c|}{ Distances ( $(\AA)$} \\
\hline Ni1-P1 & $2.2345(14)$ & $\mathrm{Ni} 2-\mathrm{C} 43$ & $1.778(6)$ \\
\hline Ni1-P3 & $2.2379(17)$ & $\mathrm{Ni2}-\mathrm{C} 44$ & $1.767(7)$ \\
\hline $\mathrm{Ni1}-\mathrm{C} 41$ & $1.774(6)$ & C41-O1 & $1.144(7)$ \\
\hline $\mathrm{Ni1}-\mathrm{C} 42$ & $1.763(6)$ & $\mathrm{C} 42-\mathrm{O} 2$ & $1.151(7)$ \\
\hline Ni2-P2 & $2.2364(16)$ & $\mathrm{C} 43-\mathrm{O} 3$ & $1.150(6)$ \\
\hline $\mathrm{Ni2-P4}$ & $2.221(2)$ & $\mathrm{C} 44-\mathrm{O} 4$ & $1.155(7)$ \\
\hline \multicolumn{4}{|c|}{ Angles (deg) } \\
\hline C41-Ni1-C42 & $113.6(3)$ & C43-Ni2-C44 & $115.9(3)$ \\
\hline P1-Ni1-P3 & $109.59(6)$ & $\mathrm{P} 2-\mathrm{Ni2}-\mathrm{P} 4$ & $124.72(7)$ \\
\hline
\end{tabular}

Table 1. Selected bond distances and angles for $\left.\left[\mathrm{Ni}(\mathrm{CO})_{2}{ }^{(\mathrm{iPr}} \mathrm{PCHP}\right)\right] 2$.

The NMR and IR spectra of the product isolated from the decomposition of [( $\left.{ }^{\mathrm{PPr}} \mathrm{PCP}\right) \mathrm{Ni}$-OMe] (see Figures $\mathrm{S} 1$ and $\mathrm{S} 2$ in the Supplementary Material) confirm the presence of $\mathrm{CO}$ and ${ }^{i P r} \mathrm{PCHP}$ ligands but, surprisingly, not every spectral feature is in good agreement with the crystal structure shown in Figure 2. To begin with, the unique singlet resonance observed at $\delta 38.6$ ppm in its ${ }^{31} \mathrm{P}\left\{{ }^{1} \mathrm{H}\right\}$ spectrum does not agree with the low symmetry of the molecule. This could be attributed to the flexibility of the $\mathrm{Ni}_{2}\left({ }^{\text {(Pr }} \mathrm{PCHP}\right)_{2}$ framework, that might allow for the fast inversion of the relative orientations of the Ni centres, but a further inconsistency is found in the deshielding of the ${ }^{13} \mathrm{C}$ signal 
of the carbonyl groups. These give rise to a singlet at $\delta 242.9$ $\mathrm{ppm}$, while the analogous resonance of nickel( 0$)$ phosphine complexes with terminally bound CO ligands, ${ }^{[23]}$ is close to 200 ppm and is always split by coupling to the ${ }^{31} \mathrm{P}$ nuclei. In addition, the IR spectrum shows a number of intense carbonyl absorptions within the $1839-1736 \mathrm{~cm}^{-1}$ range, instead of the typical symmetric and antisymmetric $\mathrm{CO}$ stretch bands observed in complexes containing $\mathrm{Ni}(\mathrm{CO})_{2}\left(\mathrm{PR}_{3}\right)_{2}$ moieties at ca. 2000 and $1850 \mathrm{~cm}^{-1}$ respectively. ${ }^{[23]}$ Combined, the deshielding of the ${ }^{13} \mathrm{C}$ carbonyl resonance and low frequency of $v(\mathrm{CO})$ IR bands point to the presence of bridging rather than terminally bound carbonyls ligands, as seen in the crystal structure. The easiest explanation for this disagreement is that an exceptional crystal corresponding to a minor product was selected for the $\mathrm{X}$ ray analysis. This conclusion finds support in the observation of two weak absorptions at 1990 and $1929 \mathrm{~cm}^{-1}$ in the IR spectrum of a representative sample from which the crystals were picked (Figure S2) that fit the expectations for the dimer impurity. Furthermore, ${ }^{31} \mathrm{P}\left\{{ }^{1} \mathrm{H}\right\}$ monitoring of the decomposition of [( $\left.\left.{ }^{\mathrm{iPr} P C P}\right) \mathrm{Ni}-\mathrm{OMe}\right]$ (see inset in Figure 1-D) reveals a pair of triplets corresponding to an $\mathrm{A}_{2} \mathrm{X}_{2}$ spin system with $\delta_{\mathrm{A}}=45.3 \mathrm{ppm}$, $\delta_{\mathrm{X}}=39.3 \mathrm{ppm}$ and $J_{\mathrm{AX}}=13.1 \mathrm{~Hz}$ consistent with a binuclear species containing two non-equivalent $\mathrm{NiP}_{2}$ fragments connected with long range ${ }^{31} \mathrm{P}_{-}{ }^{31} \mathrm{P}$ couplings. Most likely, this species corresponds to the crystal structure shown in Figure 2. The intensity ratio of the $\mathrm{A}_{2} \mathrm{X}_{2}$ signal to the $\delta 38.6$ singlet is higher when the thermolyses is performed at $80^{\circ} \mathrm{C}$ than at $90^{\circ} \mathrm{C}$, and decreases as the reaction advances. This suggests that the binuclear carbonyl complex is an intermediate that precedes the species responsible for the $\delta 38.6$ singlet, the ultimate product of the decomposition process.

In order to grow $X$ ray quality crystals of the $\delta 38.6 \mathrm{ppm}$ product, a solution of $\left[\left({ }^{\mathrm{iPr}} \mathrm{PCP}\right) \mathrm{Ni}-\mathrm{OMe}\right]$ in methanol was allowed to rest at $100{ }^{\circ} \mathrm{C}$ in a tightly sealed ampoule. The decomposition proceeds slowly in this solvent, but the product crystallizes as it forms. After 5 days, a mixture of red crystals and an amorphous white solid had deposited on the walls of the ampoule. The latter appeared to be insoluble in most solvents, but the crystals readily dissolved in $\mathrm{C}_{6} \mathrm{D}_{6}$. Their NMR spectra confirmed that this is the same material obtained in toluene.

Figure 3 shows the crystal structure determined using a red crystal obtained from the material deposited during thermolysis of $\left[\left({ }^{\mathrm{iPr}} \mathrm{PCP}\right) \mathrm{Ni}-\mathrm{OMe}\right]$ in methanol. Selected bond distances and angles are listed on Table 2. The complex is a tetranuclear carbonyl of composition $\left[\mathrm{Ni}_{4}(\mu-\mathrm{CO})_{5}\left(\mu-{ }^{\mathrm{iPr}} \mathrm{PCHP}\right)_{2}\right]$. Consistent with the observed release of free ${ }^{\mathrm{iPr}} \mathrm{PCHP}$ during its formation, the molecule contains only one diphosphine ligand per each pair of nickel atoms and, in agreement with the spectroscopic data discussed above, it does not contain terminal, but bridging carbonyl ligands.

The four nickel atoms core adopt a butterfly arrangement that could also be described as a tetrahedron open in one of its sides, with each of the five $\mathrm{Ni}-\mathrm{Ni}$ bonds bridged by a carbonyl. The Ni-Ni bond lengths are within the $2.37-2.56 \AA$ range, whilst the nonbonding distance between $\mathrm{Ni} 1$ and $\mathrm{Ni} 2$ is appreciably longer, 2.8955(8) $\AA$. The latter two atoms are connected by one of the bridging ${ }^{\mathrm{iPr}} \mathrm{PCHP}$ ligands, and the second ligand bridges the Ni3-Ni4 bond (the butterfly "body" axis), which, remarkably,

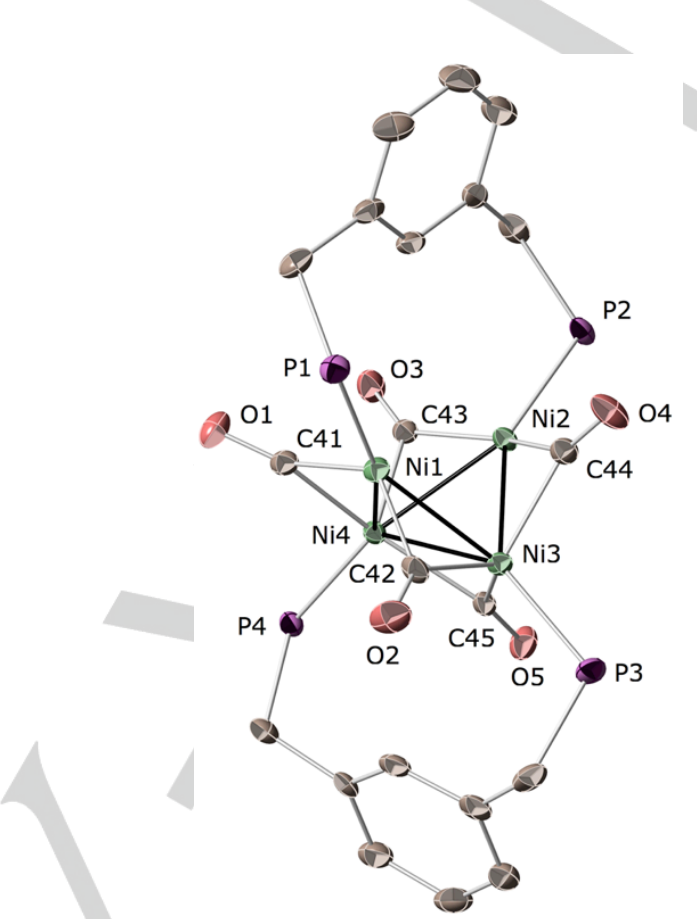

Figure 3. ORTEP plot with $40 \%$ probability ellipsoids of $\left[\mathrm{Ni}_{4}(\mu-\mathrm{CO})_{5}(\mu-\right.$ ${ }^{\text {iPr }} \mathrm{PCHP}_{)_{2}}$ ]. iPr substituents on phosphorus atoms have been omitted for clarity.

Table 2. Selected interatomic distances and angles for $\left[\mathrm{Ni}_{4}(\mu-\mathrm{CO})_{5}(\mu-\right.$ $\left.{ }^{i \operatorname{Pr}} \mathrm{PCHP}\right)_{2}$ ].

\begin{tabular}{|c|c|c|c|}
\hline $\mathrm{Ni} 1 \cdots \mathrm{Ni} 2$ & $2.8955(8)$ & $\mathrm{Ni3}-\mathrm{C} 44$ & $1.937(4)$ \\
\hline $\mathrm{Ni1}-\mathrm{Ni3}$ & $2.3737(8)$ & $\mathrm{Ni2}-\mathrm{C} 44$ & $1.881(5)$ \\
\hline $\mathrm{Ni1}-\mathrm{Ni4}$ & $2.4181(8)$ & $\mathrm{Ni} 2-\mathrm{C} 43$ & $1.912(5)$ \\
\hline $\mathrm{Ni} 2-\mathrm{Ni3}$ & $2.4480(8)$ & $\mathrm{Ni} 4-\mathrm{C} 43$ & $1.916(4)$ \\
\hline $\mathrm{Ni} 2-\mathrm{Ni} 4$ & $2.3940(8)$ & $\mathrm{Ni4}-\mathrm{C} 45$ & $1.957(5)$ \\
\hline $\mathrm{Ni3}-\mathrm{Ni} 4$ & $2.5675(8)$ & $\mathrm{Ni3}-\mathrm{C} 45$ & $1.915(5)$ \\
\hline $\mathrm{Ni1}-\mathrm{C} 42$ & $1.847(5)$ & Ni1-P1 & $2.1751(13)$ \\
\hline $\mathrm{Ni3}-\mathrm{C} 42$ & $1.931(5)$ & $\mathrm{Ni2}-\mathrm{P} 2$ & $2.1687(12)$ \\
\hline Ni1-C41 & $1.856(5)$ & $\mathrm{Ni3}-\mathrm{P} 3$ & $2.1958(13)$ \\
\hline $\mathrm{Ni4}-\mathrm{C} 41$ & $1.967(5)$ & Ni4-P4 & $2.2037(12)$ \\
\hline \multicolumn{4}{|c|}{ Dihedral Ni1-Ni3-Ni4-Ni2: 90.50(3) } \\
\hline
\end{tabular}

Is the longest of the five $\mathrm{Ni}-\mathrm{Ni}$ bonds. The fact that the longer intermetallic distances are precisely those bridged by the diphosphine suggests that, due to its wide bite angle, this ligand stretches rather than reinforces the $\mathrm{Ni}-\mathrm{Ni}$ interactions. 
Even though the tetranuclear cluster structure is in good agreement with most spectroscopic data, its low molecular symmetry is still in apparent conflict with the simplicity of the NMR spectra. Specifically, the single-signal ${ }^{31} \mathrm{P}\left\{{ }^{1} \mathrm{H}\right\}$ spectrum and the unique ${ }^{13} \mathrm{C}$ resonance observed for all $\mathrm{CO}$ carbon atoms appear to be inconsistent with the four non-equivalent $\mathrm{P}$ atoms and five carbonyl groups observed in the solid-state structure. However, both features can be readily explained on the basis of rapid intramolecular exchange of bridging carbonyl ligands, a common phenomenon in carbonyl cluster complexes. ${ }^{[24,25]}$ This process rapidly averages bonding and non-bonding $\mathrm{Ni}-\mathrm{Ni}$ interactions, thus it can be held responsible for the observation of a single type of ${ }^{31} \mathrm{P}$ and carbonyl ${ }^{13} \mathrm{C}$ nuclei. However the absence of observable ${ }^{31} \mathrm{P}_{-}{ }^{13} \mathrm{C}$ couplings could be due either to vey low effective coupling constants or to intermolecular $\mathrm{CO}$ exchange.

There are in the literature several tetranuclear carbonylphosphine complexes of $\mathrm{Pt}^{[25]}$ and $\mathrm{Pd}^{[26]}$ with butterfly cores similar to that of $\left[\mathrm{Ni}_{4}(\mu-\mathrm{CO})_{5}\left(\mu-{ }^{\mathrm{IPr}} \mathrm{PCHP}\right)_{2}\right]$. However, this type of structure is unprecedented for $\mathrm{Ni}$, in spite of the wealth of polynuclear carbonyl complexes known for this element. Among these, their closer relatives are compounds of the type $\left[\mathrm{Ni}_{4}(\mathrm{CO})_{6}\left(\mathrm{PR}_{3}\right)_{4}\right]$, prepared by Bochmann almost 25 years ago from $\mathrm{Ni}(\mathrm{cod})_{2}, \mathrm{PR}_{3}$ and $\mathrm{CO}^{[27]}$ These contain closed shell tetrahedral $\mathrm{Ni}_{4}$ frameworks with 60 valence electrons. In contrast, $\left[\mathrm{Ni}_{4}(\mu-\mathrm{CO})_{5}\left(\mu-{ }^{\mathrm{PPr}} \mathrm{PCHP}\right)_{2}\right]$, with one less carbonyl ligand and a 58 electron count, is electronically unsaturated according to the NAE rule. As discussed above, the reason why this open structure is favoured over the closed tetrahedral framework could lie in the destabilization of the $\mathrm{Ni}-\mathrm{Ni}$ interactions by the wide bite angle of the ${ }^{\mathrm{iPr}} \mathrm{PCHP}$ diphosphine.

Methoxide is known to lose hydrogen in the coordination sphere of certain transition metals to yield carbonyl ligands, ${ }^{[28]}$ and this process has considerable interest as a model for catalytic acceptorless alcohol dehydrogenation. ${ }^{[2]}$ Reactions of this type usually require second or third row transition elements, but a couple of examples involving nickel have been reported recently. ${ }^{[21]}$ The mechanism of this process has seldom been studied in detail, ${ }^{[29]}$ but it is usually assumed that it starts with $\mathrm{BHE}$ from the methoxide, and the formaldehyde resulting undergoes sequential activation of both $\mathrm{C}-\mathrm{H}$ bonds followed by $\mathrm{H}_{2}$ elimination. In the decomposition of [( $\left.\left.{ }^{\mathrm{Pr}} \mathrm{PCP}\right) \mathrm{Ni}-\mathrm{OMe}\right]$, formaldehyde generated in the BHE step must be released from the coordination sphere of the metal to afford the observed hydride $\left[\left({ }^{\mathrm{iPr}} \mathrm{PCP}\right) \mathrm{Ni}-\mathrm{H}\right]$. In consequence, the dehydrogenation step involves further interaction between both products, as shown in Scheme 2. Likely, the result would be a monomeric nickel carbonyl species that evolves into the final polynuclear carbonyl complexes. The factor that causes the different outcome of the decomposition of the palladium and nickel methoxides is the ability of the hydride intermediate to react with formaldehyde without immediately reverting to the initial methoxide. In the case of $\mathrm{Pd}$, this could be prevented by the thermal instability of such hydride.

The final stages of the decomposition of the $\mathrm{Ni}$ methoxide correspond to the transformation of the monomeric carbonyl intermediate into the observed polynuclear carbonyls $\left[\mathrm{Ni}(\mathrm{CO})_{2}(\mu-\right.$ $\left.\left.{ }^{\mathrm{IPr}} \mathrm{PCHP}\right)\right]_{2}$ and $\left[\mathrm{Ni}_{4}(\mu-\mathrm{CO})_{5}\left(\mu-{ }^{\mathrm{iPr}} \mathrm{PCHP}\right)_{2}\right]$. Note that neither of these two compounds has the $1: 1 \mathrm{Ni} / \mathrm{CO}$ stoichiometry of the monomeric carbonyl intermediate, therefore their formation requires some degree of decomposition. On the other hand, although the binuclear carbonyl has the same 1:1 $\mathrm{Ni} /$ diphosphine ratio than the methoxide precursor, formation of the cluster requires the release of half the originally present diphosphine. As discussed previously, the binuclear carbonyl precedes the tetranuclear species, which is also in accordance with the higher temperatures required to complete the formation of the latter. This might suggest that the formation of the cluster could be favoured because its open structure is specially stable, or, in other words, because this product represents a "thermodynamic sink" for the system. However, in spite of our efforts, we failed to assemble an alternative synthetic method for this compound. For example, inspired in Bochmann's cluster carbonyl syntheses, ${ }^{[27]}$ we carried out the reaction of $\mathrm{Ni}(\operatorname{cod})_{2}$, ${ }^{\mathrm{iPr}} \mathrm{PCHP}$ and $\mathrm{CO}$ either at room temperature or at $100{ }^{\circ} \mathrm{C}$, but this afforded mixtures of different species, none of which with the characteristic ${ }^{31} \mathrm{P}$ signatures of $\left[\mathrm{Ni}(\mathrm{CO})_{2}(\mu-\mathrm{PrPCHP})\right]_{2}$ or $\left[\mathrm{Ni}_{4}(\mu-\mathrm{CO})_{5}\left(\mu-{ }^{\mathrm{iPr}} \mathrm{PCHP}\right)_{2}\right]$. These were not observed when $\left[\left({ }^{\mathrm{Pr} P C P}\right) \mathrm{Ni}-\mathrm{H}\right]$ was treated with an stoichiometric amount or excess of $\mathrm{CO}$ in an NMR tube.

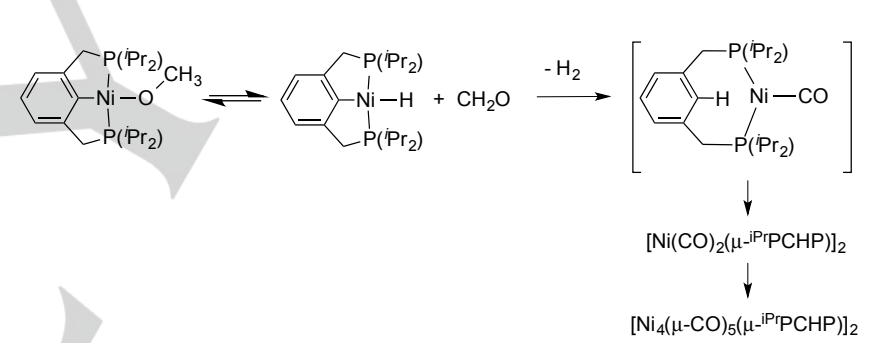

Scheme 2. Decomposition of the nickel methoxide [( $\left.\left.{ }^{i \mathrm{Pr}} \mathrm{PCP}\right) \mathrm{Ni}-\mathrm{OMe}\right]$.

\section{Kinetic models for the decomposition of [( $\left.\left.{ }^{\mathrm{iPr}} \mathrm{PCP}\right) \mathrm{M}-\mathrm{OMe}\right]$ complexes.}

Neither in methanol nor in benzene do the decompositions of the $\mathrm{Pd}$ or the $\mathrm{Ni}$ methoxide complexes obey simple kinetics. These can be conveniently monitored using the decay of methoxide ${ }^{31} \mathrm{P}$ resonances. Figure 4 shows first order plots of the decay of the $\left[\left({ }^{\mathrm{iPr}} \mathrm{PCP}\right) \mathrm{Pd}-\mathrm{OMe}\right]$ at $50{ }^{\circ} \mathrm{C}$ in both solvents. As can be seen, they are approximately linear in their first stages but in the long term they deviate and become slower than expected for first order kinetics (dashed lines). A similar plot for the decomposition of $\left[\left({ }^{\text {iPr PCP }}\right) \mathrm{Ni}-\mathrm{OMe}\right]$ a $90^{\circ} \mathrm{C}$ in $\mathrm{C}_{6} \mathrm{D}_{6}$ (see Figure S3, Supplementary Material) also shows significant deviations from the first order rate law.

The observed deviations from the first order rate law can be explained by assuming the reversibility of the BHE reactions. In the case of the $\mathrm{Pd}$ methoxide, formaldehyde will accumulate shifting the BHE equilibrium to the side of the starting material. This causes observed slowing of the rate of methoxide decay with regard to simple first order kinetics. For nickel, the situation is more complex because formation of the final carbonyl 
compounds consumes the formaldehyde generated in the $\mathrm{BHE}$ step, but this process is not fast enough to prevent the buildup of transitory accumulations of these intermediates.

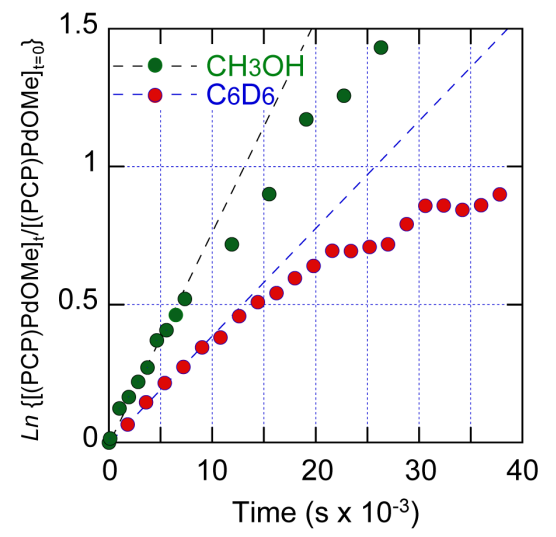

Figure 4. First-order plots for the decomposition of $\left[\left({ }^{\mathrm{iPr}} \mathrm{PCP}\right) \mathrm{Pd}-\mathrm{OMe}\right]$ in methanol and $\mathrm{C}_{6} \mathrm{D}_{6}$ at $50{ }^{\circ} \mathrm{C}$. Dashed lines represent fits for the points observed within the first $2.5 \mathrm{~h}$. Initial rate constants: $7.5 \times 10^{-5} \mathrm{~s}^{-1}$ (methanol) and $4.0 \times 10^{-5} \mathrm{~s}^{-1}$ (benzene).

Although the intermediate hydride complexes are easily detected in the ${ }^{1} \mathrm{H}$ NMR spectra reaction mixtures, the characteristic $\mathrm{CH}_{2} \mathrm{O}$ resonance at $\delta 8.68$ (in $\mathrm{C}_{6} \mathrm{D}_{6}$ ) could only be positively identified as a relatively weak signal during the decomposition of [( $\left.\left.{ }^{\mathrm{iPr} P C P}\right) \mathrm{Ni}-\mathrm{OMe}\right]\left(\right.$ at 90 or $\left.100{ }^{\circ} \mathrm{C}\right)$. This is consistent with the known tendency of formaldehyde to undergo reversible oligomerization, ${ }^{[30]}$ as noted in the literature for the decomposition reactions of other transition metal methoxide complexes. ${ }^{[16 a, 17 a, 19 b]}$ However, our experiments indicate that formaldehyde oligomers are reactive enough to allow equilibration of methoxide and hydride complexes. This could involve either the dissociation of such oligomers back into $\mathrm{CH}_{2} \mathrm{O}$, or their ability to react directly with the hydride complexes. In an attempt to cast light on this matter, solutions of the nickel and palladium hydrides $\left[\left({ }^{\mathrm{iPr}} \mathrm{PCP}\right) \mathrm{M}-\mathrm{H}\right]$ in $\mathrm{C}_{6} \mathrm{D}_{6}$ were shaken with paraformaldehyde at the room temperature. In both cases the initial ${ }^{31} \mathrm{P}$ resonance of the hydride was rapidly replaced by a cluster of signals at $\delta 54-55 \mathrm{ppm}(\mathrm{Ni})$ or $\sim 57 \mathrm{ppm}(\mathrm{Pd})$ which suggests the formation of mixtures of closely related products possibly containing polyoxymethylene chains $\left(-\left(\mathrm{OCH}_{2}\right)_{n^{-}}\right)$ attached to the metal atom. Because depolymerisation of formaldehyde is slow at room temperature, it is unlikely that these reactions could occur by direct reaction with monomeric $\mathrm{CH}_{2} \mathrm{O}$ units. Rather, the hydrides seem to react directly with paraformaldehyde, possibly at the reactive terminal edges of the polymer. On heating the mixtures at $60{ }^{\circ} \mathrm{C}$ their ${ }^{31} \mathrm{P}$ NMR spectra become simpler, showing a main signal at $\delta 59.5 \mathrm{ppm}(\mathrm{Ni})$ or $59.7 \mathrm{ppm}(\mathrm{Pd})$. These are close to those of the corresponding methoxides (52.6 and $56.1 \mathrm{ppm}$, respectively), but they are not coincident. Although these experiments do not demonstrate that the methoxide complexes can be regenerated by direct reaction of the corresponding hydrides with formaldehyde oligomers, they at least suggest that the hydride complexes are reactive enough to render this a likely possibility.

For the purpose of kinetic analysis, the decomposition of the alkoxides can be represented by the reaction schemes shown in Scheme 3. Each of them contains a reversible BHE process and an irreversible step corresponding to the transformation of the hydride in the final products. The latter marks the difference between the $\mathrm{Pd}$ and the $\mathrm{Ni}$ systems, formaldehyde being allowed to accumulate in the former case $\left(k_{2}\right)$ whilst it is consumed in the latter $\left(k_{2}^{\prime}\right)$. The behaviour of formaldehyde is modelled with a reversible step meaning its conversion to oligomeric or unreactive form, $\left(\left[\mathrm{CH}_{2} \mathrm{O}\right]_{0}\right)$. This part of the model is not intended to be an accurate description of the real process, but it should be regarded as a flexible mathematical artefact that reduces the availability of formaldehyde and may describe either actual lower concentration of the monomer or the diminished reactivity of its oligomers.

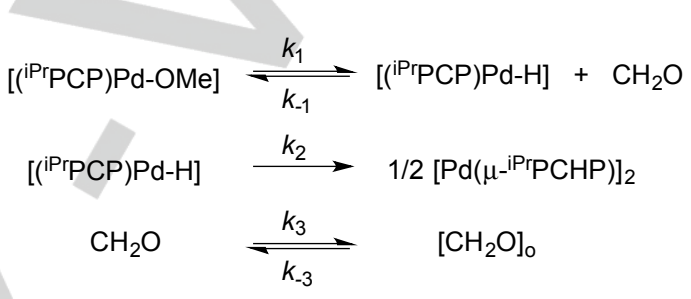

$$
\begin{aligned}
& {\left[(\text { PPrPCP)Ni-OMe }] \frac{k_{1}}{k_{-1}}\left[\left({ }^{(P r} P C P\right) N i-H\right]+\mathrm{CH}_{2} \mathrm{O}\right.} \\
& {\left[\left({ }^{\text {PrPCP }}\right) \mathrm{Ni}-\mathrm{H}\right]+\mathrm{CH}_{2} \mathrm{O} \stackrel{k_{2}^{\prime}}{\longrightarrow} \text { Carbonyl complexes + }{ }^{\text {PPrPCHP }}}
\end{aligned}
$$

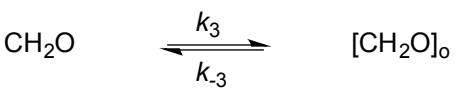

Scheme 3. Simplified kinetic models for the decomposition of methoxide complexes [( $\left.\left.{ }^{\mathrm{iPr} P C P}\right) \mathrm{M}-\mathrm{OMe}\right](\mathrm{M}=\mathrm{Ni}, \mathrm{Pd})$.

In spite of their apparent simplicity, the models shown in Scheme 3 give rise to differential equation sets that cannot be easily integrated by analytical methods. The difficulty stems from the fact that the rates of the forward and backward reactions of the BHE equilibrium and those of the irreversible steps are all comparable, in consequence common simplifications, such as fast pre-equilibrium or stationary concentration of the intermediates, cannot be applied. Furthermore, the fact that both the hydride and formaldehyde (or reactive formaldehyde oligomers) build up significant accumulations during the process introduces complicated mathematical relationships in the differential equation sets. However, the rate constant of the direct $\mathrm{BHE}$ reaction $\left(k_{1}\right)$ can be reasonably estimated from the initial rate of disappearance of the methoxide complexes, when the hydride concentration is small enough to be neglected.

As can be seen in Figure 4, the decomposition of $\left[\left({ }^{\mathrm{iPr}} \mathrm{PCP}\right) \mathrm{Pd}-\mathrm{OMe}\right]$ is faster in methanol than in benzene, as previously reported for the related $\left[{ }^{\mathrm{tBu}} \mathrm{PCP}\right) \mathrm{Pd}$-OMe] system. ${ }^{[20 \mathrm{~b}]}$ However, the initial rate constants, $7.5 \times 10^{-5}$ and $4.0 \times 10^{-5} \mathrm{~s}^{-1}$, 
respectively are not too disparate and translate in just 0.45 $\mathrm{kcal} \cdot \mathrm{mol}^{-1}$ in terms of free activation energies $\left(\Delta \Delta \mathrm{G}^{\ddagger}\right)$. In contrast, the decomposition of the $\mathrm{Ni}$ methoxide in methanol is appreciably slower than in benzene. This is not surprising since, as commented before, the methoxide complex is partially regenerated when the hydride reacts with methanol. Since methanol has markedly different effects on the decomposition of the $\mathrm{Pd}$ and $\mathrm{Ni}$ methoxides, we decided to focus our investigation on the decomposition in benzene. However, the mechanism catalytic effect of methanol on the decomposition of the palladium hydride is a relevant process and will be the subject of a separate investigation in our laboratories.
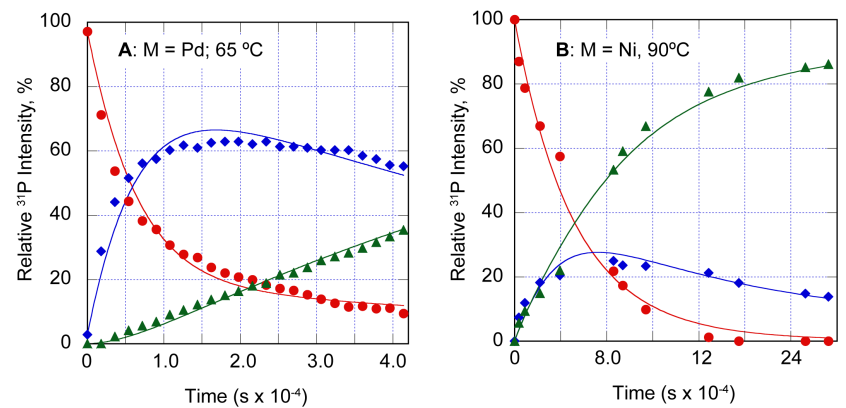

$$
\begin{aligned}
& \because[(\text { PrPCP)M-OMe] } \\
& \because[\text { [(iPrPCP)M-H] } \\
& - \text { Products }
\end{aligned}
$$

Figure 5. Evolution of the main species involved in the thermolyses (in $\mathrm{C}_{6} \mathrm{D}_{6}$ ) of $\left[\left({ }^{i \mathrm{Pr}} \mathrm{PCP}\right) \mathrm{Pd}-\mathrm{OMe}\right]$ at $65^{\circ} \mathrm{C}(\mathrm{A})$ and $\left[\left({ }^{\mathrm{iPr}} \mathrm{PCP}\right) \mathrm{Ni}-\mathrm{OMe}\right]$ at $90^{\circ} \mathrm{C}(\mathrm{B})$. Products are $[\mathrm{Pd}(\mu-\mathrm{PrPCHP})]_{2}$ in $\mathrm{A}$ and the sum of nickel carbonyl complexes plus free ${ }^{\mathrm{iPr}} \mathrm{PCHP}$ in $\mathrm{B}$. Solid traces represent the best fit of experimental data to kinetic models in Scheme 3.

Table 3. Rate and Equilibrium Constants Estimated for the decomposition of Methoxides [ $\left.\left({ }^{\mathrm{Pr}} \mathrm{PCP}\right) \mathrm{M}-\mathrm{OMe}\right](\mathrm{M}=\mathrm{Pd}, \mathrm{Ni})$ in $\mathrm{C}_{6} \mathrm{D}_{6}$, according to Scheme 3 .

\begin{tabular}{lllll}
\hline$[\mathrm{M}]$ & $\begin{array}{l}\text { Temp., } \\
{ }^{\circ} \mathrm{C}\end{array}$ & $k_{1}, \mathrm{~s}^{-1}$ & $K_{1}, \mathrm{~mol} \cdot \mathrm{I}^{-1}$ & $\begin{array}{l}k_{2}, \mathrm{~s}^{-1} \mathrm{or} \\
\mathrm{k}_{2}, \mathrm{~s}^{-1} \cdot \mathrm{I} \cdot \mathrm{mol}^{-1}\end{array}$ \\
\hline $\mathrm{Pd}$ & 25 & $3.3(6) \times 10^{-6}$ & $2(1) \times 10^{-3}$ & -- \\
$\mathrm{Pd}$ & 35 & $1.25(2) \times 10^{-5}$ & $7.0(4) \times 10^{-3}$ & -- \\
$\mathrm{Pd}$ & 50 & $6.4(2) \times 10^{-5}$ & $1.4(2) \times 10^{-2}$ & $3(2) \times 10^{-7}$ \\
$\mathrm{Pd}$ & 65 & $1.81(3) \times 10^{-4}$ & $4.9(3) \times 10^{-2}$ & $1.50(1) \times 10^{-6}$ \\
$\mathrm{Pd}$ & 80 & $2.27(8) \times 10^{-4}$ & $3.8(3) \times 10^{-2}$ & $3.7(1) \times 10^{-5}$ \\
$\mathrm{Ni}$ & 50 & $6.0(8) \times 10^{-7}$ & $2(1) \times 10^{-4}$ & -- \\
$\mathrm{Ni}$ & 65 & $2.9(2) \times 10^{-6}$ & $4.7(11) \times 10^{-4}$ & $1.4(4) \times 10^{-4}$ \\
$\mathrm{Ni}$ & 80 & $1.0(2) \times 10^{-5}$ & $1.5(11) \times 10^{-3}$ & $2.7(1) \times 10^{-3}$ \\
$\mathrm{Ni}$ & 90 & $1.2(7) \times 10^{-5}$ & $2(4) \times 10^{-3}$ & $8(1) \times 10^{-3}$ \\
$\mathrm{Ni}$ & 100 & $4.2(3) \times 10^{-5}$ & $3(3) \times 10^{-3}$ & $9(3) \times 10^{-3}$ \\
\hline
\end{tabular}

In order to gather additional information on the mechanism of the decomposition of the $\mathrm{Ni}$ and $\mathrm{Pd}$ methoxides, we investigated their decomposition in $\mathrm{C}_{6} \mathrm{D}_{6}$ at different temperatures, using ${ }^{31} \mathrm{P}$ NMR to monitor their advance. The temperature ranges selected were $25-80^{\circ} \mathrm{C}$ for the palladium methoxide and $50-100{ }^{\circ} \mathrm{C}$ for the nickel derivative. To cope with the complicated kinetics of these reactions, we fitted the experimental data to the kinetic models using numeric methods. ${ }^{[31]}$ Figure 5 provides two representative examples of these fits (solid lines), and similar plots for the rest of experiments are shown in the Supplementary Material (Figure S4). In the case of the Ni complex, the sum of the intensities of the signals due to the final products (viz., carbonyl complexes and free ${ }^{\mathrm{iPr}} \mathrm{PCHP}$ ligand) has been plotted as a single magnitude. As can be seen, satisfactory numerical fits were obtained in all cases, which indicates that the proposed kinetic models provide a quantitative description of the experimental systems. Attempts to use alternative models, for instance, including irreversible BHE, suppressing the formaldehyde oligomerization step, or, in the nickel model, replacing the reaction of the hydride with formaldehyde with direct transformation of the methoxide into the final carbonyl products in competition with $\mathrm{BHE}$, invariably led to poorer results.

The most relevant kinetic and thermodynamic parameters obtained from numeric fits are collected in Table 3. In this table, reverse BHE rate constants $k_{-1}$ have been used to compute the corresponding equilibrium constants $K_{1}\left(=k_{1} / k_{-1}\right)$. The $K_{1}$ data allow complete characterization of the BHE equilibria. A plot of $\ln \left(K_{1}\right) v s$. the inverse of the absolute temperature (van't Hoff plot,

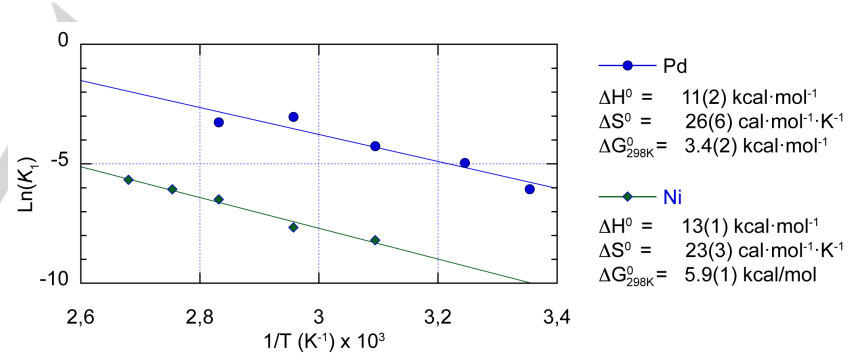

Figure 6. Van't Hoff plot of the dependence of equilibrium constants $K_{1}$ on the temperature and thermodynamic functions for BHE of [( $\left.\left.{ }^{\mathrm{iPr}} \mathrm{PCP}\right) \mathrm{M}-\mathrm{OMe}\right]$.

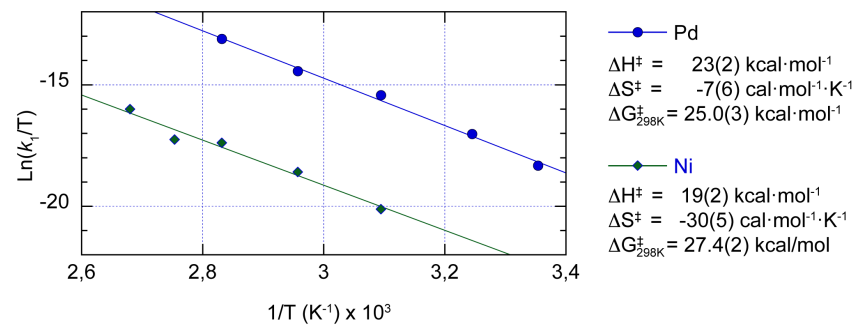

Figure 7. Eyring plot of the dependence of the rate constants $k_{1}$ on the temperature and activation parameters for $\mathrm{BHE}$ of $\left.\left[{ }^{\mathrm{iPr}} \mathrm{PCP}\right) \mathrm{M}-\mathrm{OMe}\right]$ 
Figure 6) shows reasonable linear correlations that provide the corresponding thermodynamic parameters, $\Delta \mathrm{G}^{\circ}, \Delta \mathrm{H}^{\circ}$ and $\Delta \mathrm{S}^{\circ}$. Both BHE processes are moderately endergonic, more so for $\mathrm{Ni}$ than for $\mathrm{Pd}$. The corresponding $\Delta \mathrm{G}^{\circ}$ values are $+3.4(2)$ and $+5.9(1) \mathrm{kcal} \cdot \mathrm{mol}^{-1}$ for $\mathrm{M}=\mathrm{Pd}$ and $\mathrm{Ni}$, respectively, at $25^{\circ} \mathrm{C}$.

Activation parameters and the free energy barriers $\left(\Delta \mathrm{G}^{\ddagger}\right)$ involved for $\mathrm{BHE}$ can be calculated from the dependence of $k_{1}$ rate constants on temperature. Eyring plots of $k_{1}$ are shown in Figure 7. The faster rate of BHE of the $\mathrm{Pd}$ methoxide as compared to the $\mathrm{Ni}$ derivative translates in a difference of 2-3 $\mathrm{kcal} \cdot \mathrm{mol}^{-1}$ in the free energy barriers $\left(\Delta \Delta \mathrm{G}^{\ddagger}{ }_{\mathrm{Ni}-\mathrm{Pd}}=2.3(3)\right.$ $\mathrm{kcal} \cdot \mathrm{mol}^{-1}$ at $25{ }^{\circ} \mathrm{C}$ or $3.7(3)$ at $\left.80^{\circ} \mathrm{C}\right)$. However, activation enthalpies show the opposite trend, i.e., $\Delta \mathrm{H}^{\ddagger}$ is higher for palladium than nickel by $5.5(3) \mathrm{kcal} \cdot \mathrm{mol}^{-1}$. Therefore, the higher size of the free energy barrier associated to BHE for the $\mathrm{Ni}$ complex arises purely from entropy effects.

The range of data available for the irreversible decomposition of the hydrides $\left(k_{2}\right.$ and $\left.k_{2}^{\prime}\right)$ is limited because these are not observed at the lower temperatures. This prevents the calculation of reliable activation parameters, but mean $\Delta \mathrm{G}^{\ddagger}$ values for the decomposition of $\left[\left({ }^{i P r} \mathrm{PCP}\right) \mathrm{Pd}-\mathrm{H}\right]\left(k_{2}\right)$ and the reaction of $\left[\left({ }^{i \mathrm{Pr}} \mathrm{PCP}\right) \mathrm{Ni}-\mathrm{H}\right]$ with $\mathrm{CH}_{2} \mathrm{O}\left(k_{2}^{\prime}\right)$ over the available temperature ranges are $27.4(1)\left(50-80^{\circ} \mathrm{C}\right)$ and $25(3) \mathrm{kcal}^{\circ} \cdot \mathrm{mol}^{-1}$ $\left(65-100^{\circ} \mathrm{C}\right)$, respectively. The barrier associated to $k_{2}$ is close to the value estimated from the decomposition of a pure sample of $\left[\left({ }^{\mathrm{iPr}} \mathrm{PCP}\right) \mathrm{Pd}-\mathrm{H}\right]$ in benzene at $100^{\circ} \mathrm{C}\left(\Delta \mathrm{G}^{\ddagger} \approx 29 \mathrm{kcal} \cdot \mathrm{mol}^{-1}\right)$.

\section{DFT modelling of the decomposition mechanisms.}

In order to gain a better understanding of the mechanisms involved in the BHE step and the subsequent hydrogen transfer to the pincer ligand we modelled them using DFT and the wellknown B3LYP functional. To facilitate calculations, geometries of simplified molecular models in which the bulky ${ }^{\mathrm{P}} \mathrm{Pr}$ substituents were replaced with methyl groups (i. e., ${ }^{\mathrm{Me}} \mathrm{PCP}$ instead of ${ }^{\mathrm{iPr}} \mathrm{PCP}$ ), were optimized using a computationally inexpensive double-zeta basis set (BS1, see Experimental for details), and energies were refined later with single point calculations using a triple-zeta basis set (BS2) and including solvent effects. While this strategy is fairly usual in computational chemistry, ${ }^{[32]}$ it sometimes leads to minor inconsistencies, particularly when evaluating very small energy barriers for intermediate steps. These are apparent in the energies for some transition states that become slightly below those of the corresponding products when computed at the BS2 level, but with no consequences for the general conclusions.

Although the kinetic models discussed in the precedent section provide a general framework for the theoretical modeling, it is difficult to anticipate the details of the mechanisms of the decomposition of the [ $\left.\left.{ }^{\mathrm{iPr}} \mathrm{PCP}\right) \mathrm{M}-\mathrm{OMe}\right]$ complexes, even at the relatively simple BHE stage. It is usually assumed that in order to enable hydrogen abstraction by the metal centre a coordination vacancy has to be generated in cis to the alkoxide ligand. For 16-e pincer complexes, the free axial position has the potential to act as the required cis coordination vacancy, but the empty orbitals available in the $z$ direction $\left(4 p_{z}\right.$ for $\mathrm{Ni}$ or $5 p_{z}$ for
$\mathrm{Pd}$ ) lie at relatively high energies. Otherwise, dissociation of one of the pincer $\mathrm{P}$ donor atoms could generate a coordination vacancy in the coordination plane, but this could be difficult in the rigid environment provided by the PCP scaffold. An alternative would be dissociative $\beta$-hydrogen abstraction. This has in fact been invoked to explain $\mathrm{BHE}$ in $\mathrm{Pd}(\mathrm{II})$ complexes containing rigid pincer ligands. ${ }^{[13 b, 19 b, c, 20 b]}$ It has been experimentally found that this type of mechanism requires the presence of alcohol as a solvent or co-solvent in order to promote the otherwise energetically costly heterolysis of the $M$ OR bond. ${ }^{[19 b, c]}$ Accordingly, our attempts to locate a stationary point corresponding to a well-defined ionic pair $\left\{\left[\left({ }^{\mathrm{Me}} \mathrm{PCP}\right) \mathrm{Pd}\right]^{+}[\mathrm{OMe}]\right\}$ in the potential energy surface of $\left[\left({ }^{\mathrm{Me}} \mathrm{PCP}\right) \mathrm{Pd}-\mathrm{OMe}\right](\mathrm{Pd} 1)$ without the assistance of polar solvents, either as a stable intermediates or a transition state, did not meet success. Therefore, since most of our experimental work was carried out using benzene as solvent, we focused on mechanisms that proceed without $\mathrm{M}-\mathrm{OMe}$ bond dissociation.

A transition state (Ni-TS12) for the BHE of the nickel methoxide model [ $\left({ }^{\mathrm{Me}} \mathrm{PCP}\right) \mathrm{Ni}$-OMe] (Ni1) was located by tracing out the inverse reaction trajectory, $i$. e., by approaching a formaldehyde molecule to the hydride complex [( $\left.\left.{ }^{\mathrm{Me}} \mathrm{PCP}\right) \mathrm{Ni}-\mathrm{H}\right]$ (Ni2) along the axis perpendicular to the coordination plane at progressively decreasing distances. This strategy proved unsuccessful for the analogous Pd mehtoxide, Pd1, but optimization of a model built on the basis of the structural features of Ni-TS12 led to a somewhat different kind of transition state, Pd-TS45. The optimized structures of Ni-TS12 and PdTS45 are shown in Figure 8. Ni-TS12 can be described as a late transition state for hydrogen transfer, conformed by weakly interacting $\mathrm{CH}_{2} \mathrm{O}$ and $\left[\left({ }^{\mathrm{Me}} \mathrm{PCP}\right) \mathrm{Ni}-\mathrm{H}\right]$ fragments. The $\mathrm{C}-\mathrm{O}$ bond length $(1.27 \AA)$ is close to that computed for free formaldehyde $(1.21 \AA)$ and compared to $\mathrm{Ni2}$, the $\mathrm{Ni}-\mathrm{H}$ bond of $\mathrm{Ni}-\mathrm{TS} 12$ is only slightly elongated (from 1.52 to $1.54 \AA$ ). However weak, the interaction with the $\mathrm{CH}_{2} \mathrm{O}$ fragment causes a noticeable distortion of the square-planar $\left[\left({ }^{\mathrm{Me}} \mathrm{PCP}\right) \mathrm{Ni}-\mathrm{H}\right]$ fragment, the $\mathrm{H}-\mathrm{Ni}$ C angle narrowing to $168.3^{\circ}$. In contrast, the geometry of the $\mathrm{Pd}$ centre in Pd-TS45 can be described as a trigonal bipyramid, where the metal-bound $\mathrm{C}$ and $\mathrm{H}$ atoms occupy the axial positions and the $\mathrm{O}$ and both $\mathrm{P}$ atoms configure the equatorial

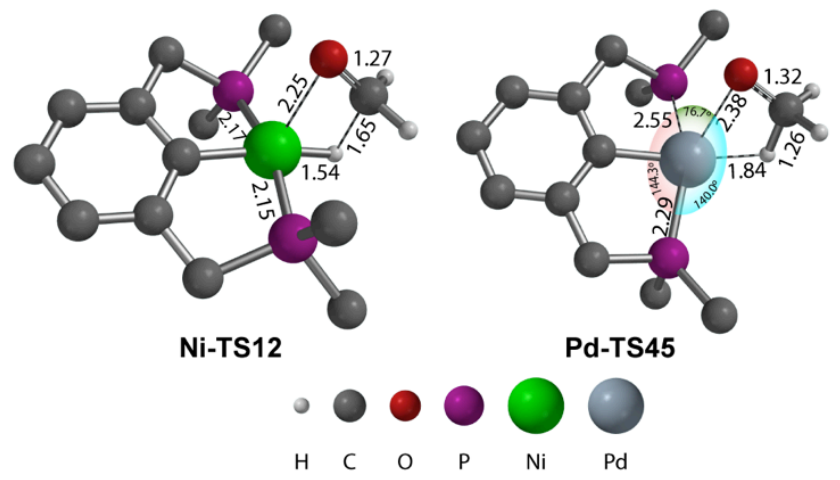

Figure 8. Optimized structures of BHE transition states Ni-TS12 and Pd-TS45 showing selected distances $(\AA)$ and angles (deg). Non-essential $\mathrm{H}$ atoms have been omitted for clarity. 

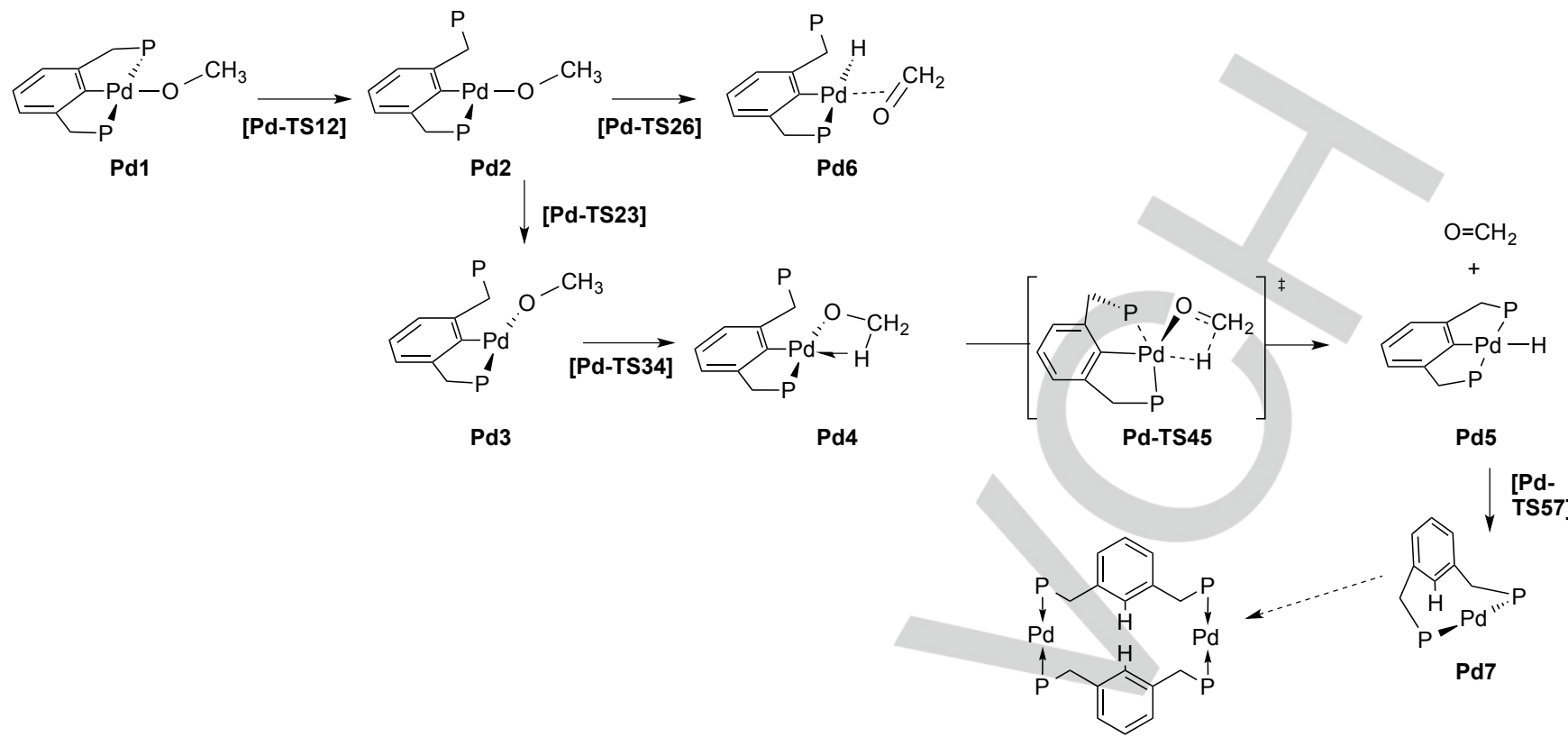

$[\mathrm{Pd}(\mu-\mathrm{PCHP})]_{2}$

Scheme 4. Decomposition mechanism of the palladium methoxide complex

plane, as indicated by the sum of the P-Pd-P and both P-Pd-O angles, $361^{\circ}$. Significantly, one of the Pd-P bonds $(2.55 \AA)$ is appreciably longer than the other $(2.29 \AA)$, which indicates that in this transition state the hydrogen transfer motion is coupled somehow with the displacement of a $\mathrm{PMe}_{2}$ fragment.

In order to ascertain the details the mechanism of the BHE processes, Intrinsic Reaction Coordinate (IRC) calculations were carried out on Ni-TS12 and Pd-TS45. In the former case, the IRC calculation confirmed the identity of $\mathrm{Ni}-\mathrm{TS} 12$ as the expected transition state for $\beta$-hydrogen abstraction. On the other hand Pd-TS45 is also a BHE transition state but, as shown in Scheme 4, it does connect the hydride Pd5 not to the starting methoxide complex Pd1 but to Pd4, an "open" alkoxide in which one of $\mathrm{PMe}_{2}$ arms of the pincer ligand bonds has been replaced with an agostic interaction involving one of the $\beta$-hydrogen atoms of the OMe ligand. In Pd-TS45 this hydrogen atom is removed from carbon while the $\mathrm{PMe}_{2}$ unit recovers its former coordination position. Simultaneously, the formaldehyde molecule is ejected from the Pd centre.

The configuration of Pd4 differs from that of the starting complex Pd1 in the cis arrangement of the methoxy ligand with regard to the $\mathrm{Pd}-\mathrm{C}$ bond. This forced us to seek a pathway connecting Pd1 to Pd4. As depicted in Scheme 4, this route begins with the opening of one of the pincer side arms in Pd1 to afford the T-shaped trans-alkoxide Pd2, which then rearranges to its cis isomer $\mathbf{P d} \mathbf{3}$ via $\mathbf{P d}$-TS23, a transition state with a trigonal-planar Pd centre. Next, the terminal methoxide ligand of Pd3 rotates to allow the $\beta$-agostic interaction, giving rise to Pd4 As can be seen in the energy profile (Figure 9), hydrogen abstraction proceeds very easily from the latter intermediate, which is only $3.3 \mathrm{kcal} \cdot \mathrm{mol}^{-1}$ below the BHE transition state $\mathbf{P d}$ -
TS45. The step going from Pd-TS45 to $\mathbf{P d 5}+\mathrm{CH}_{2} \mathrm{O}$ is strongly exergonic $\left(\Delta \mathrm{G}^{\circ}=-25.9 \mathrm{kcal} \cdot \mathrm{mol}^{-1}\right)$, but the overall free energy balance for the BHE from Pd1 is slightly unfavorable, $\Delta \mathrm{G}^{\circ}=+1.7$ $\mathrm{kcal} \cdot \mathrm{mol}^{-1}$, due to the energy cost of the initial breaking of the $\mathrm{Pd}-\mathrm{P}$ bond of the original pincer fragment.

The relative complexity of the Pd1 $\rightarrow$ Pd5 pathway poses the question of whether a simpler mechanism could operate in which BHE takes place directly from the coordinatively unsaturated methoxide Pd2. The corresponding BHE transition state, Pd-TS26, connects $\mathbf{P d 2}$ to the $\mathrm{Pd}(\mathrm{II})$ hydrideformaldehyde complex Pd6, which could then evolve into Pd5 by means of a series of transformations including cis/trans

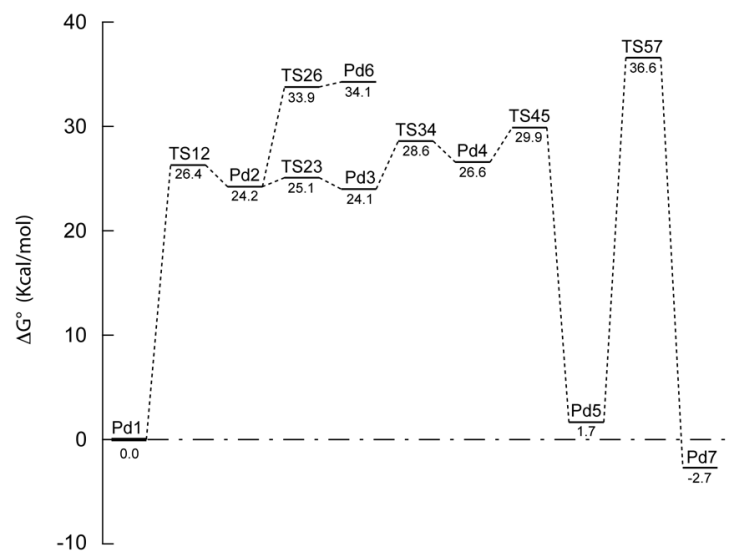

Figure 9. Free energy profile for the $\mathrm{Pd}$ methoxide decomposition mechanism shown in Scheme 4 (at $298 \mathrm{~K}, \mathrm{kcal} \cdot \mathrm{mol}^{-1}$ relative to Pd1). Prefixes Pd- have been removed from transition state codes for simplicity. 
isomerization and formaldehyde dissociation (the slightly higher energy of the product Pd6 over the TS at the BS2 level is a calculation artefact). However, Pd-TS26 is significantly higher in energy than Pd-TS45 (by $4.5 \mathrm{kcal} \cdot \mathrm{mol}^{-1}$ ), therefore we did not pursue the study of pathway beyond Pd6.

The decomposition of the $\mathrm{Pd}$ methoxide concludes with a reductive $\mathrm{C}-\mathrm{H}$ coupling reaction that affords the final $\mathrm{Pd}(0)$ species. The mechanism for this seemingly simple transformation is not obvious. In principle intramolecular migration of the hydride ligand of Pd5 to the Pd-bound carbon atom should be prevented by the rigid trans configuration imposed by the pincer ligand. In the experimental system, this process could be facilitated by traces of methanol which, as previously mentioned, is an efficient catalyst for this transformation. ${ }^{[7]}$ However, since $\left[\left({ }^{i \mathrm{Pr}} \mathrm{PCP}\right) \mathrm{Pd}-\mathrm{H}\right]$ does decompose in $\mathrm{C}_{6} \mathrm{D}_{6}$ above $50^{\circ} \mathrm{C}$ in the absence of methanol, we decided to examine the intramolecular migration of the hydride ligand to the trans $\mathrm{Pd}-\mathrm{C}$ bound atom, in spite of its apparent difficulty. Such transformation would involve bending of the initially linear $\mathrm{C}-\mathrm{Pd}-\mathrm{H}$ linkage until carbon and hydrogen approach to a bonding distance. The transition state Pd-TS57 is attained when the $\mathrm{C}-\mathrm{Pd}-\mathrm{H}$ angle reaches $66.1^{\circ}$ and leads to the monomeric $\operatorname{Pd}(0)$ species Pd7. The structures of Pd-TS57 and $\mathbf{P d} 7$ are shown in Figure 10. The Pd $\cdots \mathrm{C}-\mathrm{H}$ linkage in Pd-TS57 is reminiscent of the internal $\pi$-arene interaction found by van Koten in coordinatively unsaturated $\mathrm{Pt}$ (II) "arenium" complexes of type $[(\mathrm{NCN}) \mathrm{Pt}]^{+}{ }^{[33]}$ Even though going from Pd5 to $\mathbf{P d 7}$ is exergonic by $2.7 \mathrm{kcal} \cdot \mathrm{mol}^{-1}$, the $\mathrm{P}-\mathrm{Pd}-\mathrm{P}$ angle in the latter, $147.5^{\circ}$, departs from the optimum linear arrangement and evidences an important degree of strain in this mononuclear $\mathrm{Pd}(0)$ species. This strain is released by its conversion into the corresponding $\mathrm{Pd}(0)$ dimer, $[\mathrm{Pd}(\mu-\mathrm{PCHP})]_{2}$, as observed experimentally. We previously calculated that such process is thermodynamically favourable by ca. $14 \mathrm{kcal} \cdot \mathrm{mol}^{-1}{ }^{[7]}$

Transition state TS-Pd57 is $34.9 \mathrm{kcal} \cdot \mathrm{mol}^{-1}$ higher than that of the hydride Pd5. Although the energy difference is larger than the experimentally determined $\Delta G^{\ddagger}$ for the decomposition of $\left[\left({ }^{\mathrm{iPr}} \mathrm{PCP}\right) \mathrm{Pd}-\mathrm{H}\right] \quad\left(27.4 \mathrm{kcal} \cdot \mathrm{mol}^{-1}\right)$, the difference is not overwhelming. This result suggests that even if the $\mathrm{C}-\mathrm{H}$ coupling process might be facilitated by traces of $\mathrm{MeOH}$ in the

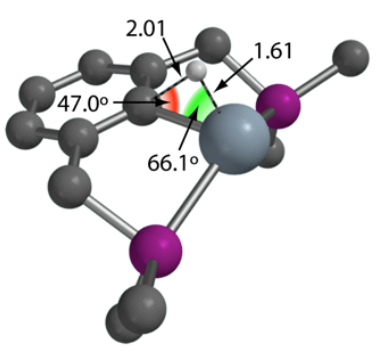

Pd-TS57

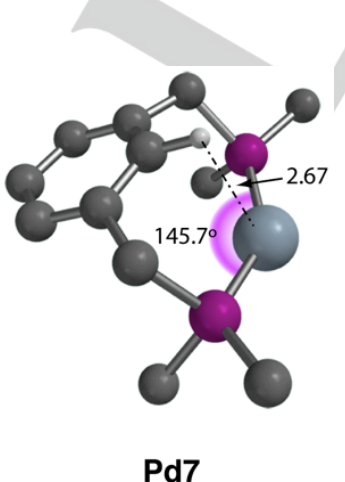

Figure 10. Optimized structures of Pd-TS57 and Pd7 showing selected distances $(\AA)$ and angles (deg). Non-essential hydrogen atoms have been omitted for clarity. For the atom color code see Figure 8. experimental system, the intramolecular mechanism is also feasible, especially at moderately high temperatures. Although surprising, the facile bending of the $\mathrm{C}-\mathrm{Pd}-\mathrm{H}$ angle is reminiscent of the free motion of hydride ligands in the dynamic conformational exchange of $\mathrm{Pt}(\mathrm{II})$ and $\operatorname{Ir}(\mathrm{I})$ complexes reported recently by Conejero and Lledós. ${ }^{[34]}$

As mentioned previously, the IRC calculation on Ni-TS12 showed that this transition state connects the starting methoxide complex, Ni1, with a hydride-formaldehyde complex, Ni2 (see Scheme 5). As can be seen in the energy profile for this process (Figure 11), the energies of $\mathbf{N i - T S 1 2}$ and $\mathbf{N i 2}$ are very similar (actually, the single point calculation at the BS2 level places Ni2 $2.8 \mathrm{kcal} \cdot \mathrm{mol}^{-1}$ above Ni-TS12). Formaldehyde binds loosely in $\mathrm{Ni} 2$ and dissociation of this complex into hydride $\mathrm{Ni3}$ plus free formaldehyde is an endothermic but thermodynamically favourable process (i. e., entropy-driven) that takes place without energy barrier. Thus $\mathrm{Ni2}$ is predicted to be an undetectable intermediate in equilibrium with the hydride $\mathbf{N i 3}$. However, the ability of the square-planar $\mathrm{Ni}(\mathrm{II})$ hydride to bind formaldehyde may be an important factor determining the last stage of the decomposition process.

In contrast with the mobility of the hydride in $\mathbf{P d 5}$, bending the $\mathrm{C}-\mathrm{M}-\mathrm{H}$ angle in $\mathrm{Ni} 3$ beyond $90^{\circ}$ is energetically costly, and

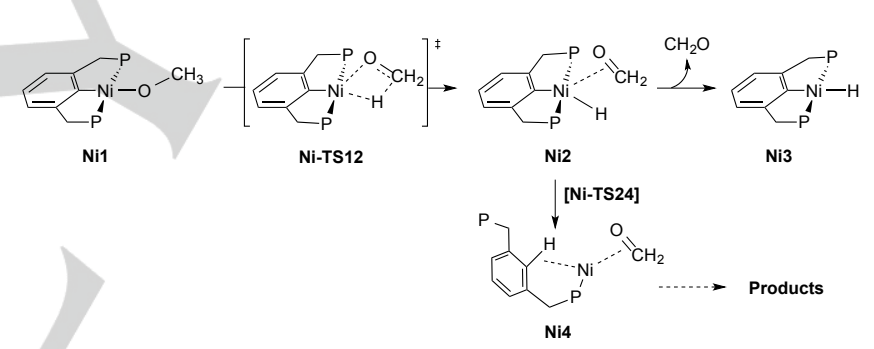

Scheme 5. Decomposition mechanism of the nickel methoxide complex

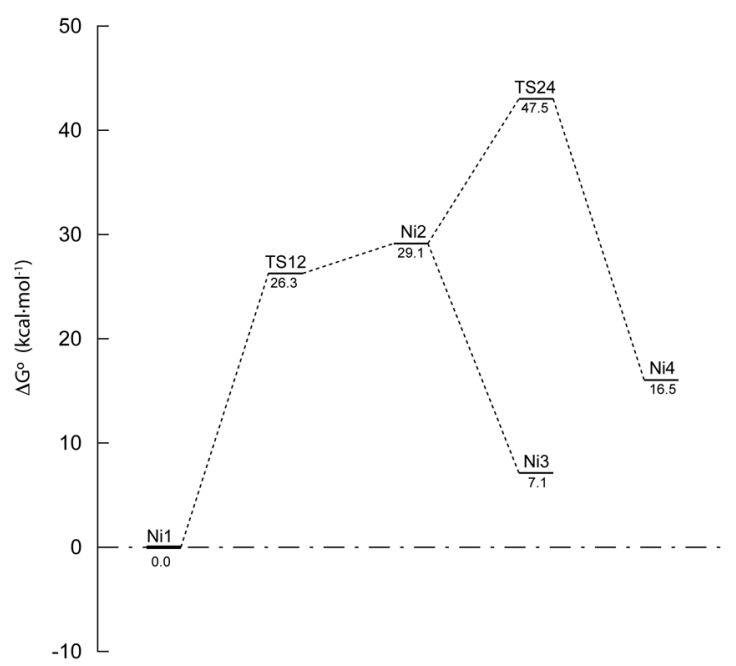

Figure 11. Free energy profile for the $\mathrm{Ni}$ methoxide decomposition mechanism shown in Scheme 5 (at $298 \mathrm{~K}, \mathrm{kcal} \cdot \mathrm{mol}^{-1}$ relative to $\mathrm{Ni1}$ ). Prefixes $\mathrm{Ni}$ - have been removed from transition state codes for simplicity. 
the nickel analogue of transition state Pd-TS57 could not be located. However, $\mathrm{C}-\mathrm{H}$ coupling becomes feasible when formaldehyde coordinates to $\mathrm{Ni}$, i.e., starting from complex $\mathbf{N i 2}$, via Ni-TS24. This is a reasonable result, as it has been known for a long time that electron acceptor ligands promote reductive elimination of $\mathrm{Ni}(\mathrm{II})$ complexes. ${ }^{[35]} \mathrm{An}$ IRC analysis on Ni-TS24 showed that $\mathrm{C}-\mathrm{H}$ coupling ends up in the $\mathrm{Ni}(0)$ complex $\mathrm{Ni4}$, a three-coordinate $\mathrm{Ni}(0)$ formaldehyde complex containing a $\mathrm{Ni}-\mathrm{H}$ agostic interaction and a pending $\mathrm{CH}_{2} \mathrm{PMe}_{2}$ arm. This species provides the entry to a pathway leading to the final $\mathrm{Ni}(0)$ carbonyl complexes, as discussed below. The structures of $\mathbf{N i 2}$, transition state $\mathrm{Ni}-\mathrm{TS} 24$ and the $\mathrm{Ni}(0)$ formaldehyde complex $\mathrm{Ni4}$ are compared in Figure 12. A remarkable feature of Ni-TS24 is that, although the $\mathrm{Ni}-\mathrm{H}$ bond is being broken, it is slightly shorter than in Ni2. This can be explained by the influence of electron acceptor $\mathrm{CH}_{2} \mathrm{O}$ ligand, which is trans to the hydride in the transition state.

Overall, our calculations provide a satisfactory description of the BHE process, in line with the experimental data gathered for the decomposition of both [( $\left.\left.{ }^{\mathrm{iPr} P C P}\right) \mathrm{M}-\mathrm{OMe}\right]$ complexes. Thus, the calculations successfully reproduce endothermic character of the BHE processes, more pronounced for $\mathrm{Ni}$ than for $\mathrm{Pd}$, and their reversibility. Accordingly, both the $\mathrm{Ni}$ and the $\mathrm{Pd}$ methoxides would be thermally stable, were not BHE connected to irreversible hydride transfer processes. These irreversible decomposition processes mark the main difference between the nickel and palladium systems.

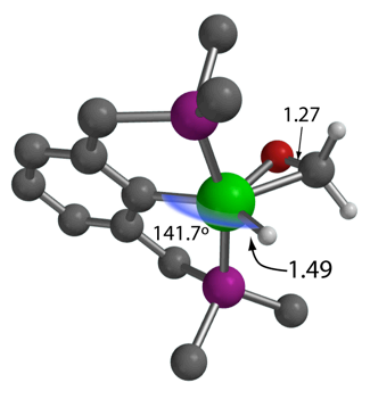

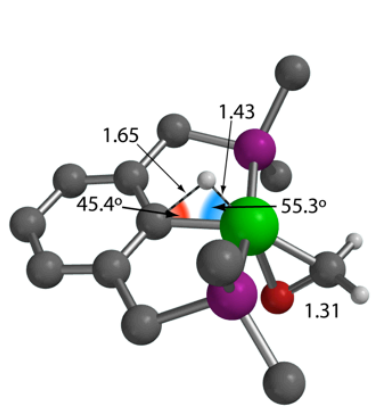

Ni-TS24

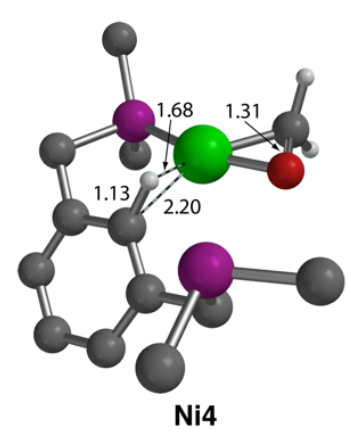

Figure 12. Optimized structures of $\mathrm{Ni}-2, \mathrm{Ni}-\mathrm{TS} 24$ and $\mathrm{Ni} 4$ showing selected distances $(\AA)$ and angles (deg). Non-essential hydrogen atoms have been omitted for clarity. For the atom colour code see Figure 8.
In addition, the free energies of the BHE transition states $\mathrm{Ni}$ TS12 and Pd-TS45 relative to the corresponding methoxides, 26.3 and $29.9 \mathrm{kcal} \cdot \mathrm{mol}^{-1}$, are in good agreement with the experimental BHE $\Delta \mathrm{G}^{\ddagger}$ values in the ${ }^{\mathrm{iPr}} \mathrm{PCP}$ system (values extrapolated to $25^{\circ} \mathrm{C}: \mathrm{Ni}, 27.5 ; \mathrm{Pd} 25.03 \mathrm{kcal} \cdot \mathrm{mol}^{-1}$, see Figure 7). There is an apparent inconsistency in the fact that computed barrier for $\mathrm{Ni}$ is lower than for $\mathrm{Pd}$, while the experiment indicates the opposite trend. This could be attributed to the imperfect modelling of the bulky $\mathrm{P}^{\mathrm{i}} \mathrm{Pr}_{2}$ groups with $\mathrm{PMe}_{2}$. Dissociation of the pincer $\mathrm{CH}_{2} \mathrm{PR}_{2}$ arms is probably facilitated by steric hindrance and this very likely contributes to decrease the experimental energy barrier of $\mathrm{BHE}$ for $\mathrm{Pd}$, but has little effect in the case of $\mathrm{Ni}$, which does not require $\mathrm{M}-\mathrm{P}$ bond scission. On the other hand, Eyring analyses of the experimental rate constants $k_{1}$ indicate that the higher energy barrier for the BHE of the Ni methoxide is due to the entropy factor. Computational evaluation of entropy could be inaccurate for a number of reasons, from loss of conformational freedom in the simplified $\mathrm{PMe}_{2}$ groups to solvation effects that are not described by the continuum solvent model used in our calculations. However, it is worth noting that the solvation model accurately reproduces the general influence of the solvent polarity on the size of the BHE barrier for the Pd methoxide. Re-evaluation of the energy of PdTS45 using methanol instead of benzene as the solvent leads to a slightly lower $\Delta \mathrm{G}^{\ddagger}, 29.52 \mathrm{kcal} \cdot \mathrm{mol}^{-1}$ (relative to Pd1). The $\Delta \Delta \mathrm{G}^{\ddagger}$ difference between the free activation energies computed in benzene and methanol, $0.41 \mathrm{kcal} \cdot \mathrm{mol}^{-1}$ (essentially temperatureindependent between 25 and $65^{\circ} \mathrm{C}$ ) matches very well the experimental figure, $0.45 \mathrm{kcal} \cdot \mathrm{mol}^{-1}$, which strongly suggests that the acceleration of the decomposition rate observed in methanol is due to the influence of solvent polarity and not to changes in the mechanism.

As commented before, the experimental data provide no indications of what could be the mechanism of formation of the nickel carbonyl complexes. Our calculations suggest that formaldehyde might induce $\mathrm{C}-\mathrm{H}$ reductive elimination and trigger the dehydrogenation of the coordinated formaldehyde molecule. The details are represented in the route labelled "Mechanism A" in Scheme 6. This begins with the aforementioned hydride transfer step to afford $\mathrm{Ni4}$. Next, the formaldedhyde ligand rotates via transition state $\mathrm{Ni}$-TS45, shifting its coordination mode from $\eta^{2}-C, O$ to $\eta^{3}-H, C, H$ in order to allow the nickel centre in $\mathrm{Ni5}$ to interact simultaneously with both $\mathrm{C}-\mathrm{H}$ bonds. This enables one of these bonds to oxidatively add to $\mathrm{Ni}(0)$ affording the hydrido-formyl intermediate Ni6. As expected, ${ }^{[36]} \mathrm{Ni6}$ is thermodynamically unstable and readily undergoes $\mathrm{CO}$ extrusion (i. e., the reversal of $\mathrm{CO}$ insertion into a $\mathrm{Ni}-\mathrm{H}$ bond), to afford a carbonyl, Ni7. This species evolves into carbonyl Ni10 through a series of thermodynamically downhill steps comprising trans/cis isomerization, reductive elimination of $\mathrm{H}_{2}$ and recoordination of the pending $\mathrm{P}$-donor group, represented collectively in Scheme 6 with a dashed arrow. We have not explored these final steps in detail, as they are all expected to be fast and of little consequence for the process as a whole. As can be seen in the corresponding energy profile (Figure 13), the highest energy in Mechanism A corresponds to the transition state for the $\mathrm{C}-\mathrm{H}$ coupling step (Ni-TS24), which is 18.6 


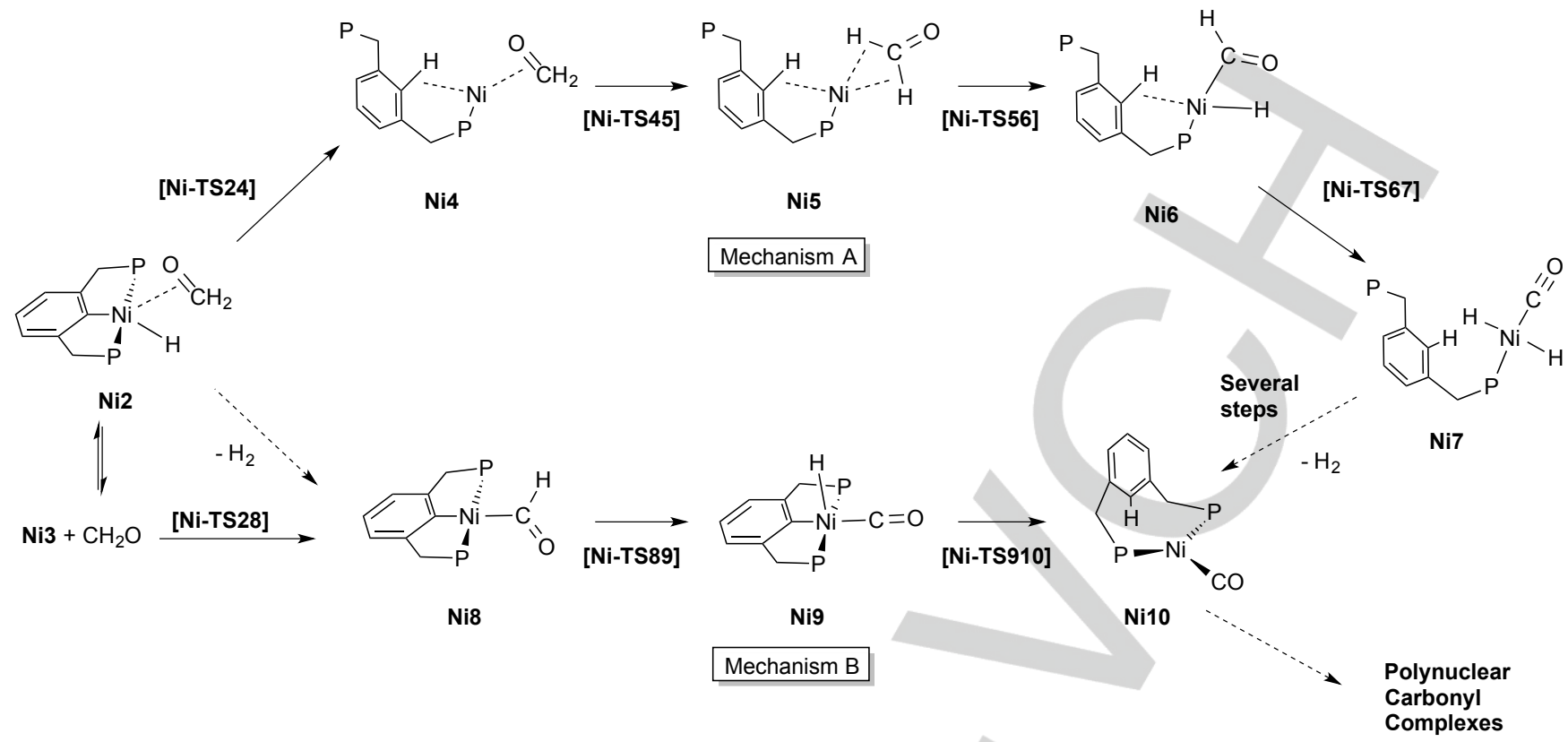

Scheme 6. Two alternative pathways for methoxide dehydrogenation starting from the hydride-formaldehyde intermediate $\mathrm{Ni2}$

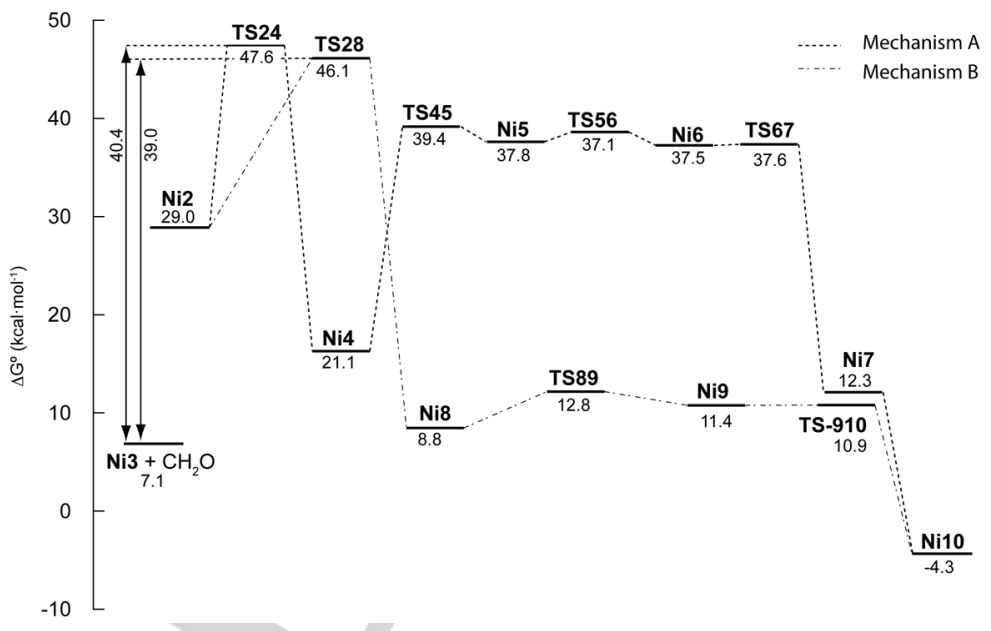

Figure 13. Free energy profiles (at $298 \mathrm{~K}, \mathrm{kcal} \cdot \mathrm{mol}^{-1}$ relative to $\mathrm{Ni1}$ ) of mechanisms $\mathrm{A}$ and $\mathrm{B}$ for formaldehyde dehydrogenation in the coordination sphere of nickel.

$\mathrm{kcal} \cdot \mathrm{mol}^{-1}$ above $\mathrm{Ni2}$. The next step, isomerization of the formaldehyde complex $\mathrm{Ni4}$ into $\mathrm{Ni5}$, also poses a considerable barrier $\left(\mathrm{Ni}-\mathrm{TS} 45-\mathrm{Ni4}=18.4 \mathrm{kcal} \cdot \mathrm{mol}^{-1}\right)$, although the irreversibility of this step is guaranteed by the even higher barrier implicit in the reversal way from Ni4 to Ni-TS24 (26.5 $\left.\mathrm{kcal} \cdot \mathrm{mol}^{-1}\right)$. The barriers for the remaining transformations in the way to formaldehyde dehydrogenation (namely, $\mathrm{C}-\mathrm{H}$ oxidative addition and $\mathrm{CO}$ extrusion, transition states $\mathrm{Ni}-\mathrm{TS} 56$ and $\mathrm{Ni}$ TS67) are much lower. Note that intermediate Ni4 is in the bottom of a deep energy well, which could render this species a detectable intermediate. However, we have found no evidence for such a $\mathrm{Ni}(0)$ intermediate in the experimental system. Another difficulty of this mechanism is that the free energy barrier for the rate-determining $\mathrm{C}-\mathrm{H}$ coupling step is too high. Transition state Ni-TS24 is $40.4 \mathrm{kcal} \cdot \mathrm{mol}^{-1}$ above the nickel hydride $\mathrm{Ni3}$ plus formaldehyde, while the experimental energy barrier measured for the irreversible transformation of $\left[\left({ }^{\mathrm{iPr}} \mathrm{PCHP}\right) \mathrm{Ni}-\mathrm{H}\right]$ into the carbonyl products (corresponding to the $k_{2}^{\prime}$ rate constant) is ca. $25 \mathrm{kcal} \cdot \mathrm{mol}^{-1}$. These problems led us to seek alternatives to this mechanism. Starting from Ni2, we explored three different pathways in which the cleavage of formaldehyde precedes the hydride transfer to the pincer ligand 
and the subsequent collapse of the cyclometallated framework: i) Isomerization of formaldehyde into a hydroxycarbene ligand (by means of a 1,2 hydrogen shift) followed by intramolecular proton transfer from hydroxycarbene to hydride; ii) Oxidative addition of a formaldehyde $\mathrm{C}-\mathrm{H}$ bond to the $\mathrm{Ni}$ (II) centre, and reductive elimination of $\mathrm{H}_{2}$ from the resulting $\mathrm{Ni}(\mathrm{IV})$ dihydride intermediate, and iii) concerted $\mathrm{H}$ abstraction from $\mathrm{CH}_{2} \mathrm{O}$ by the hydride ligand, concomitant with $\mathrm{H}_{2}$ elimination. Among these three possibilities, the latter has the lowest energy barrier. For the sake of concision, the discussion shall be limited to this pathway, depicted as "Mechanism B" in Scheme 6, but a description of mechanisms i) and ii) can be found in the Supplementary Material.

Mechanism B begins in $\mathrm{Ni2}$ with the direct transfer of a hydrogen atom from coordinated formaldehyde to the hydride ligand that causes the elimination of dihydrogen and formation of the pincer formyl complex Ni8. The corresponding transition state, Ni-TS28 (shown in Figure 14) has a distorted trigonal bipyramidal $\mathrm{Ni}$ centre with the $\mathrm{P}$ donors and a formyl group in the equatorial plane and the pincer $\mathrm{Ni}$-bound carbon atom and the hydride ligand in the axis. The hydrogen atom that is being transferred moves between the formyl carbon atom and the hydride along one of the bipyramid edges. The corresponding C$\mathrm{H}$ and $\mathrm{H}-\mathrm{H}$ distances (1.586 and $1.135 \AA$, respectively) are considerably elongated as compared to $\mathrm{C}-\mathrm{H}$ and $\mathrm{H}-\mathrm{H}$ bonds in formaldehyde $(1.110 \AA)$ and dihydrogen $(0.743 \AA)$, respectively.
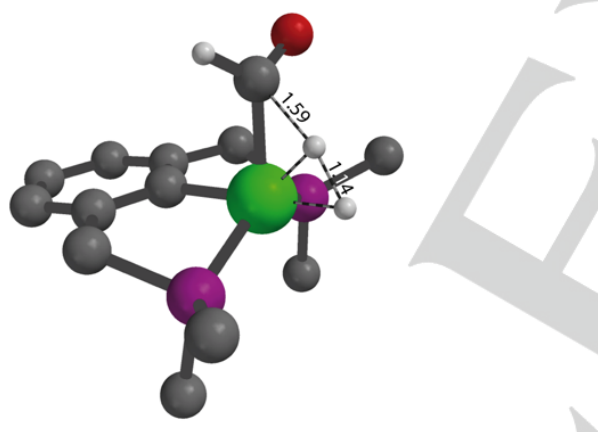

Ni-TS28

Figure 14. Optimized structure of Ni-TS28 showing selected bond distances $(\AA)$. Non-essential hydrogen atoms have been omitted for clarity. For the atom colour code see Figure 8

The configuration of $\mathrm{Ni}$-TS28 suggests that this transition sate should involve previous shift of the formaldehyde ligand in $\mathrm{Ni2}$ to allow one of its $\mathrm{C}-\mathrm{H}$ bonds interact with the metal centre (analogous to the Ni4 to Ni5 step in Mechanism A). However, a IRC calculation on $\mathrm{Ni}$-TS28 followed by full optimization of the precursor state did not converge into a $\mathrm{C}$ - $\mathrm{H}$-coordinated formaldehyde complex but instead led to $\mathrm{Ni3}$ plus free formaldehyde. This indicates that such $\eta^{2}-\mathrm{CH}$ formaldehyde complex is not a stationary point in the energy surface, hence formaldehyde must dissociate from $\mathrm{Ni2}$ prior to attain $\mathrm{Ni}-\mathrm{TS28}$, as represented in Scheme 6 . This does not represent a difficulty, since, as discussed before, $\mathrm{Ni2}$ dissociation into $\mathrm{Ni3}$ and formaldehyde is fast and reversible.

Once the hydrogen transfer is complete, $\mathrm{H}_{2}$ is released and the molecule relaxes into the square-planar formyl intermediate Ni8. The formyl hydrogen atom is then smoothly transferred to the pincer ligand, which ultimately leads to carbonyl Ni10. Figure 15 depicts the structural change in the system as the hydrogen atom is delivered from one carbon atom to another, "crossing" over the nickel atom in Ni9. CO extrusion from the formyl group is surprisingly facile (transition state Ni-TS89 means a very small energy barrier of only $3.8 \mathrm{kcal} \cdot \mathrm{mol}^{-1}$ ), notwithstanding the severe distortion of the $\mathrm{Ni}-\mathrm{C}(\mathrm{O})-\mathrm{H}$ angle from $115^{\circ}$ in the formyl Ni8 to $71^{\circ}$ in Ni-TS89. In the bipyramidal-trigonal intermediate $\mathrm{Ni9}$ the hydride ligand is in the equatorial coordination plane, while the carbonyl and the pincer $\mathrm{C}$ atom sit in the axial positions. Ni9 is only a local minimum in the potential energy surface, because Ni9', a geometric isomer in which the hydride and $\mathrm{CO}$ ligands invert their relative positions (i. e., with the carbonyl ligand in the equatorial plane and the hydride in the axis) is $6.2 \mathrm{kcal} \cdot \mathrm{mol}^{-1}$ more stable. However, with the hydride and the Ni-bound $\mathrm{C}$ atom occupying mutually cis positions, Ni9 is naturally predisposed for the next step, $\mathrm{C}-\mathrm{H}$ coupling. The barrier for this step is negligible, therefore $\mathbf{N i 9}$ is a very shortlived intermediate in the pathway to Ni10.

Transition state Ni-TS28 poses the main energy barrier in Mechanism B. Its energy, $39.0 \mathrm{kcal} \cdot \mathrm{mol}^{-1}$ relative to $\mathrm{Ni3}+\mathrm{CH}_{2} \mathrm{O}$, is still too high as compared with the $25 \mathrm{kcal} \cdot \mathrm{mol}^{-1}$ experimental activation energy deduced from the rate constant $k_{2}^{\prime}$, and only $1.4 \mathrm{kcal} \cdot \mathrm{mol}^{-1}$ less than the barrier computed for Ni-TS24 in Mechanism A $\left(40.4 \mathrm{kcal} \cdot \mathrm{mol}^{-1}\right)$. In order to refine our assessment of the energy barriers for these two mechanisms, the structures of $\mathrm{Ni} 3, \mathrm{CH}_{2} \mathrm{O}$ and of both transition states, $\mathrm{Ni}$ TS24 and Ni-TS28, were fully optimized at BS2 level. The free energy barriers for both mechanisms decrease only slightly with regard to the previously calculated values: 39.0 for $\mathrm{Ni}-\mathrm{TS} 24$ (Mechanism A) and $37.3 \mathrm{kcal} \cdot \mathrm{mol}^{-1}$ for Ni-TS28 (Mechanism B). At this point, it is not easy advancing an explanation for such a mismatch between the experimental and model systems but it must be borne in mind that the experimental values of $k_{2}^{\prime}$ are directly dependent on the actual concentration of free formaldehyde, which is indirectly inferred using a simple kinetic model that may not be realistic. On the other hand, both routes $A$ and $B$ appear to be chemically reasonable. The similarity of their energy barriers suggests that these routes could be competitive, albeit pathway B provides the most efficient and direct pathway for the observed formaldehyde hydrogenation process. 


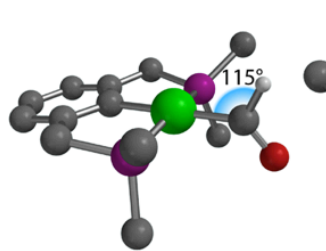

$\mathrm{Ni8}$

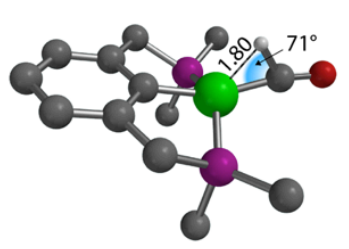

$\mathrm{Ni}-\mathrm{TS} 89$

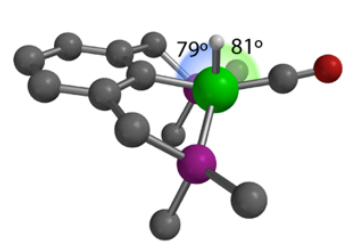

$\mathrm{Ni9}$

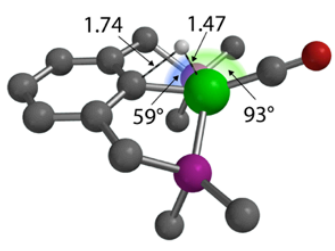

$\mathrm{Ni}-\mathrm{TS} 910$

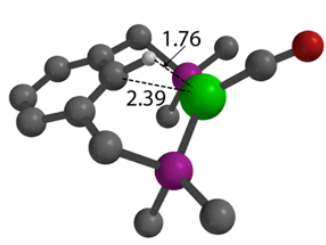

Ni10

Figure 15. Structures of intermediates and transition states along the route from $\mathbf{N i 8}$ to Ni10. Non-essential hydrogen atoms omitted for clarity. For the atom colour code see Figure 8.

\section{Conclusions}

Stabilization of nickel or palladium methoxide complexes with strongly chelating, tridentate pincer ligands does not shut down their ability to undergo BHE. The palladium methoxide $\left[\left({ }^{\mathrm{iPr}} \mathrm{PCP}\right) \mathrm{Pd}-\mathrm{OMe}\right]$ is more prone to decompose than its nickel analogue. BHE is reversible and endergonic for both complexes, and the decomposition reactions are driven by the irreversible breakdown of the pincer unit to afford different kinds of products depending on the metal: a zerovalent diphosphine complex for palladium, and polynuclear carbonyl complexes arising from formaldehyde dehydrogenation in the case of $\mathrm{Ni}$. Interestingly, although the free energy barrier for reversible BHE is higher for $\mathrm{Ni}$ than for $\mathrm{Pd}$, this is due to entropy effects and the trend for the activation enthalpies is the opposite. The reason for the different outcome of the decomoposition reactions can be traced out to the different stabilities of the corresponding complexes. While $\left[\left({ }^{i P r} \mathrm{PCP}\right) \mathrm{Pd}-\mathrm{H}\right]$ undergoes reductive elimination above $50{ }^{\circ} \mathrm{C}$, $\left[\left({ }^{i P r} \mathrm{PCP}\right) \mathrm{Ni}-\mathrm{H}\right]$ does not decompose spontaneously. The irreversible decomposition of the nickel hydride is prompted by formaldehyde generated in the BHE step.

DFT calculations have confirmed the above conclusions, and added some relevant insights into the mechanisms of both decomposition processes. The nickel methoxide undergoes $\mathrm{BHE}$ directly from its square-planar ground state through a squarepyramidal transition state, but the palladium complex has first to dissociate one of its $\mathrm{CH}_{2} \mathrm{PR}_{2}$ arms in order to release an open coordination site in the coordination plane. In both cases, the calculations confirm the reversibility of BHE and its endergonic character, more pronounced for $\mathrm{Ni}$ than for $\mathrm{Pd}$. Irreversible decomposition of the resulting $\mathrm{Pd}$ hydride can proceed in intramolecular fashion by bending the initially flat $\mathrm{C}-\mathrm{M}-\mathrm{H}$ angle until the reductive $\mathrm{C}-\mathrm{H}$ coupling ensues. This mechanism is not feasible for the nickel hydride, which only evolves on further interaction with formaldehyde released in the BHE stage, to afford a $\mathrm{Ni}(0)$ carbonyl species. Two competitive pathways (A and $B$ ) have been identified for this process. In pathway $A$ the breakdown of the cyclometallated pincer framework leads to a reactive $\mathrm{Ni}(0)$ species responsible for formaldehyde dehydrogenation. In mechanism B formaldehyde dehydrogenation precedes the collapse of the pincer unit, which is brought about in the last step of the process. Although the energy barriers for these mechanisms are not very different, mechanism B is slightly more favorable (by ca. $1.5 \mathrm{kcal} \cdot \mathrm{mol}^{-1}$ ) and probably provides the major route for the methoxide dehydrogenation process.

\section{Experimental Section}

\section{General Considerations.}

All manipulations were carried out under oxygen-free argon atmosphere, using conventional Schlenk techniques or a nitrogen filled glove box. Solvents were rigorously dried and degassed before use. Commercially available reagents were used as received. Complexes [ $\left.\left({ }^{\mathrm{iPr} P C P}\right) \mathrm{M}-\mathrm{OMe}\right]$ and $\left[\left({ }^{\mathrm{PP} P C P}\right) \mathrm{M}-\right.$ $\mathrm{H}](\mathrm{M}=\mathrm{Ni}, \mathrm{Pd})$ were prepared as described previously. ${ }^{[6 c, 7]} \mathrm{NMR}$ spectra were recorded on a Bruker DRX $400 \mathrm{MHz}$ spectrometer. Chemical shifts $(\delta)$ are in ppm. Solvent signals were used as internal standards for ${ }^{1} \mathrm{H}$ and ${ }^{13} \mathrm{C}$ spectra, but chemical shifts are reported with respect to TMS. ${ }^{31} \mathrm{P}$ spectra are referenced to external $\mathrm{PPh}_{3}$ in $\mathrm{C}_{6} \mathrm{D}_{6}(\delta-6.0 \mathrm{ppm})$. Spectral assignations were helped with monodimensional ${ }^{13} \mathrm{C}$ (gated) and bidimensional (2D) ${ }^{1} \mathrm{H}-{ }^{1} \mathrm{H}$ COSY, HMBC and ${ }^{1} \mathrm{H}-{ }^{13} \mathrm{C}$ HSQC heterocorrelation spectra. The abbreviations " $v$ " and "b" used in the spectrum listings refer to virtual coupling and broad signals, respectively. IR spectra were recorded in Nujol mull in a Bruker Vector Tensor 27 spectrophotometer. Microanalyses were performed at the Microanalytical Service of the Instituto de Investigaciones Químicas.

\section{Nickel Carbonyl Complexes.}

a) In toluene: A solution of [ $\left.\left.{ }^{\mathrm{iPr}} \mathrm{PCP}\right) \mathrm{Ni}-\mathrm{OMe}\right](128 \mathrm{mg}, 0.3 \mathrm{mmol})$ in toluene $(10 \mathrm{ml})$ was stirred at $100^{\circ} \mathrm{C}$ in a sealed ampoule for $48 \mathrm{~h}$. The solvent was evaporated under reduced pressure, the residue washed with $\mathrm{MeOH}$ and the residue dried under vacuum. The product was extracted with toluene, and the solution was filtered. Methanol was carefully added until turbidity (approximate toluene/methanol ratio $3: 1$ ) and stored at $-30^{\circ} \mathrm{C}$. The nickel cluster $\left[\mathrm{Ni}_{4}(\mu-\mathrm{CO})_{5}\left(\mu-{ }^{\mathrm{iPr}} \mathrm{PCHP}\right)_{2}\right]$ was obtained as dark red crystals in 5- $10 \%$ yield. Although in general the samples prepared in this way are analytically pure, they may contain small amounts of the dimer $\left[\mathrm{Ni}(\mathrm{CO})_{2}\left(\mu-{ }^{\mathrm{iPr}} \mathrm{PCHP}\right)\right]_{2}$, which can be 14 
easily detected by the observation of two characteristic absorption bands at 1990 and $1929 \mathrm{~cm}^{-1}$ in the IR spectrum.

b) In methanol: A solution of [( $\left.\left.{ }^{\mathrm{iPr} P C P N i}\right)-\mathrm{OMe}\right](85 \mathrm{mg}, 0.2 \mathrm{mmol})$ in methanol $(7 \mathrm{ml})$ in an airtight ampoule was submerged in an oil bath to the height of the teflon valve, and allowed to lay undisturbed at $100^{\circ} \mathrm{C}$ for 5 days. Gradual formation of dark red crystals was observed along with an amorphous white solid. After filtration the red crystals were separated manually. IR and NMR spectra confirm the identity of the crystalline material as $\left[\mathrm{Ni}_{4}(\mu-\mathrm{CO})_{5}\left(\mu-{ }^{\mathrm{iPr}} \mathrm{PCHP}\right)_{2}\right]$, and these were used for X-Ray diffraction.

Spectral and analytical data for $\left[\mathrm{Ni}_{4}(\mu-\mathrm{CO})_{5}\left(\mu-{ }^{i P r} \mathrm{PCHP}\right)_{2}\right]$ : IR (nujol mull): = $1763(\mathrm{~m}), 1769(\mathrm{~m}), 1763$ (s), 1790 (vs), $1840(\mathrm{~m})$ $\mathrm{cm}^{-1}$ (vCO). ${ }^{1} \mathrm{H}$ NMR $\left(300 \mathrm{MHz}, \mathrm{C}_{6} \mathrm{D}_{6}, 25^{\circ} \mathrm{C}\right): \delta=1.25$ (dvt, $12 \mathrm{H}$, $\left.{ }^{3} J_{\mathrm{HH}}=7.1 \mathrm{~Hz}, J^{*} \mathrm{HP}=11.5 \mathrm{~Hz}, \mathrm{CHMeMe}\right), 1.36\left(\mathrm{dvt}, 12 \mathrm{H},{ }^{3} J_{\mathrm{HH}}=\right.$ $\left.7.2 \mathrm{~Hz}, J^{*}{ }_{\mathrm{HP}}=13.6 \mathrm{~Hz}, \mathrm{CHMeMe}\right), 2.14(\mathrm{~m}, 4 \mathrm{H}, \mathrm{CHMe}), 2.91(\mathrm{~d}$, $\left.4 \mathrm{H}, J_{\mathrm{HP}}=8.0 \mathrm{~Hz}, \mathrm{CH}_{2}\right), 6.73\left(\mathrm{~d}, 2 \mathrm{H},{ }^{3} J_{\mathrm{HH}}=7.2 \mathrm{~Hz}, m-\mathrm{CH}_{\text {arom }}\right)$, $6.97\left(\mathrm{t}, 1 \mathrm{H},{ }^{3} \mathrm{~J}_{\mathrm{HH}}=8.7 \mathrm{~Hz}, p-\mathrm{CH}_{\text {arom }}\right), 7.02(\mathrm{~s}, 1 \mathrm{H}, \mathrm{PCHP}) \mathrm{ppm}$. ${ }^{13} \mathrm{C}\left\{{ }^{1} \mathrm{H}\right\}$ NMR $\left(75 \mathrm{MHz}, \mathrm{C}_{6} \mathrm{D}_{6}, 25^{\circ} \mathrm{C}\right): \delta=18.9$ (s, CHMeMe), 20.1 (s, CHMeMe), 23.5 (vt, $J^{*} \mathrm{CP}=9.0 \mathrm{~Hz}, \mathrm{CHMe}_{2}$ ), 30.6 (vt, $\left.J^{*}{ }_{\mathrm{CP}}=6.7, \mathrm{CH}_{2}\right), 127.2\left(\mathrm{~s}, m-\mathrm{CH}_{\text {arom }}\right), 127.5\left(\mathrm{~s}, p-\mathrm{CH}_{\text {arom }}\right), 131.8$ (s, PCHP), 135.3 (s, o-C arom), 242.9 (s, CO) ppm. ${ }^{31} \mathrm{P}\left\{{ }^{1} \mathrm{H}\right\}$ NMR (162 MHz, $\mathrm{C}_{6} \mathrm{D}_{6}, 25^{\circ} \mathrm{C}$ ): $\delta=38.6$ ppm. $\mathrm{C}_{45} \mathrm{H}_{72} \mathrm{Ni}_{4} \mathrm{O}_{5} \mathrm{P}_{4}$ (1051.7): calcd. C 51.39, H 6.90; found C 51.42, H, 7.08.

\section{Kinetic studies}

General procedure: The samples were prepared in the glove box: $25 \mu \mathrm{mol}$ of [ $\left.\left.{ }^{\mathrm{iPr}} \mathrm{PCP}\right) \mathrm{M}-\mathrm{OMe}\right](\mathrm{M}=\mathrm{Ni}, \mathrm{Pd})$ were dissolved in $0.6 \mathrm{ml} \mathrm{C}_{6} \mathrm{D}_{6}$. This solution was transferred to a NMR tube fitted with a gas-tight PTFE screw cap. A small amount of $\left(\mathrm{O}=\mathrm{PPh}_{3}\right.$ or $\left.\left[\left({ }^{\mathrm{iPr}} \mathrm{PCP}\right) \mathrm{M}-\mathrm{X}\right]\right)$ was used as internal standard in most cases. Monitoring the decomposition of the Pd complex was carried out placing the samples in the spectrometer probe, previously stabilized at the desired temperature. In the case of the nickel complexes (except the experiment at $100{ }^{\circ} \mathrm{C}$, which is fast enough for continuous monitoring in the NMR probe) the sample was heated in a thermostat oil bath and periodically taken to the NMR probe (2- 3 times a day). Since these experiments extended over many days, the perturbation due to the momentary cooling of the sample was deemed negligible. The decomposition process was monitored registering their ${ }^{31} \mathrm{P}\left\{{ }^{1} \mathrm{H}\right\}$ spectra regularly. The concentration of the different species was calculated from their ${ }^{31} \mathrm{P}$ signals normalized with regard to the total intensity of all the observed signals. The fit of the experimental data to the kinetic models was carried out with the DynaFit software. ${ }^{[31]}$

\section{Computational Details}

Geometries of intermediates and transition states were optimized using the package Spartan $14{ }^{[37]}$ For this purpose, the B3LYP functional and the inexpensive Basis Set 1 (BS1): 6$31 \mathrm{G}^{* *}$ basis set for $\mathrm{Ni}$ complexes, and $\mathrm{LAVCP}^{* *}$ for Pd. The latter basis set describes the lighter atoms $(\mathrm{H}, \mathrm{C}, \mathrm{O}, \mathrm{P})$ with the $6-31 \mathrm{G}^{* *}$ basis set, but uses the LANL2DZ effective core basis set for $\mathrm{Pd}$. The energy gradient criterion for geometric convergence was decreased from the Spartan default value 4.5 $x 10^{-4}$ to $10^{-5} \mathrm{erg} \cdot$ bohr in all calculations. All geometries were optimized without restrictions and vibrational calculations were performed to determine the thermal contributions to free energies (at $298.15 \mathrm{~K}$ and $1 \mathrm{bar}$ ). In all cases, the optimized structures correspond to stationary points in the potential energy surface, characterized by the absence of imaginary frequencies in local minima or by one imaginary frequency in transition states. The identity of the latter was further checked by means of Intrinsic Reaction Coordinate Calculations (IRC). Electronic energies were further refined using the software Gaussian 09. ${ }^{[38]}$ Energies were recalculated with single point energy B3LYP calculations with Basis Set 2 (BS2): $6-311++G^{* *}$ level for all atoms except for $\mathrm{Pd}$, which was described with the SDD effective core potential augmented with a $f$-polarization function. ${ }^{[39]}$ The single point calculations included the SelfConsistent Polarization Field (SCRF) with the Polarizable Continuum Model (default method in Gaussian) to model solvent effects. ${ }^{[40]}$ Benzene was used as solvent unless otherwise stated. Final free energy values were obtained by adding the thermal corrections calculated with BS1 to the solvent-corrected electronic energy terms obtained with BS2 in the single point calculations. For comparison purposes, several selected molecules were subjected to optimization using Gaussian at the BS2 level with SCRF solvent modeling. Energies computed using the "exact" and "approximate" geometries are very close and the differences are in all cases below $2 \mathrm{kcal} \cdot \mathrm{mol}^{-1}$ (see Tables S4 and S4, Supplementary Material). Absolute energies and atomic coordinates for all optimized structures are provided in the Supplementary Material.

\section{$X$-ray structure analysis for bicarbonate and carbonate complexes $\left[\mathrm{Ni}(\mathrm{CO})_{2}\left(\mu-{ }^{\text {iPr } P C H P}\right)\right]_{2}$ and $\left[\mathrm{Ni}_{4}(\mu-\mathrm{CO})_{5}(\mu-\right.$ $\left.\left.{ }^{i P r} \mathrm{PCHP}\right)_{2}\right]$}

A summary of crystallographic data and structure refinement results for these new crystalline compounds is given in Table 4. Crystals of suitable size for X-ray diffraction analyses were coated with dry perfluoropolyether, mounted on glass fibers and fixed to the goniometer head under a cold nitrogen stream ( $T=$ $100 \mathrm{~K}$ ). Data collections were performed on a Bruker-Nonius X8Apex-II CCD diffractometer using monochromatic radiation $\lambda\left(\right.$ Mo- $\left.K_{\alpha}\right)=0.71073 \AA$, by means of $\omega$ and $\phi$ scans with a width of 0.50 degree. The data were reduced (SAINT ${ }^{[41]}$ ) and corrected for absorption effects by the multi-scan method (SADABS ${ }^{[42]}$ ). The structures were solved by direct methods (SIR-2002 ${ }^{[43]}$ ) and refined against all $F 2$ data by full-matrix least-squares techniques (SHELXTL-6.12 $2^{[44]}$ ) minimizing $w\left[F_{o}^{2}-F_{c}^{2}\right]^{2}$. All nonhydrogen atoms were refined with anisotropic displacement parameters. Hydrogen atoms were included in calculated positions and allowed to ride on the attached atoms with the isotropic temperature factors ( $\bigcup_{\text {iso }}$ values) fixed at 1.2 times (1.5 times for methyl groups) those $U_{\text {eq }}$ values of the corresponding attached atoms.

CCDC-1038694 ([Ni(CO) $\left.\left.)_{2}\left(\mu{ }^{\mathrm{iPr} P C P}\right)\right]_{2}\right)$, and $1038695\left(\left[\mathrm{Ni}_{4}(\mu-\right.\right.$ $\left.\left.\mathrm{CO})_{5}\left(\mu-{ }^{\text {ipr }} \mathrm{PCHP}\right)_{2}\right]\right)$ contain the supplementary crystallographic data for this paper. These data can also be obtained free of charge from The Cambridge Crystallographic Data centre via http//www.ccdc.cam.ac.uk/data_request/cif. 
Table 4. Crystallographic data collection, intensity measurements and structure refinement parameters for $\left[\mathrm{Ni}(\mathrm{CO})_{2}\left(\mu-{ }^{\mathrm{iPr} P C P}\right)\right]_{2}$ and $\left[\mathrm{Ni}_{4}(\mu-\mathrm{CO})_{5}(\mu-\right.$ $\left.\left.{ }^{\mathrm{ipr}} \mathrm{PCHP}\right)_{2}\right]$

\begin{tabular}{|c|c|c|}
\hline & {$\left[\mathrm{Ni}(\mathrm{CO})_{2}\left(\mu-{ }^{\mathrm{iPr}} \mathrm{PCP}\right)\right]_{2}$} & $\begin{array}{l}{\left[\mathrm{Ni}_{4}(\mu-\mathrm{CO})_{5}(\mu-\right.} \\
\left.\left.{ }_{\mathrm{ipr}} \mathrm{PCHP}\right)_{2}\right]\end{array}$ \\
\hline formula & $\mathrm{C}_{44} \mathrm{H}_{71} \mathrm{Ni}_{2} \mathrm{O}_{4} \mathrm{P}_{4}$ & $\mathrm{C}_{45} \mathrm{H}_{72} \mathrm{Ni}_{4} \mathrm{O}_{5} \mathrm{P}_{4}$ \\
\hline$f w$ & 905.31 & 1051.75 \\
\hline crystal system & Monoclinic & Tetragonal \\
\hline space group & $P 2{ }_{1} / c$ & $P-421 c$ \\
\hline $\mathrm{a}, \AA$ & $14.4562(10)$ & $24.2899(5)$ \\
\hline $\mathrm{b}, \AA$ & $35.384(2)$ & $24.2899(5)$ \\
\hline $\mathrm{c}, \AA$ & $9.7504(6)$ & $16.5823(7)$ \\
\hline a, deg. & 90.00 & 90.00 \\
\hline$\beta$, deg. & $106.616(4)$ & 90.00 \\
\hline Y, deg. & 90.00 & 90.00 \\
\hline $\mathrm{V}, \AA^{3}$ & $4779.3(5)$ & $9783.5(5)$ \\
\hline$Z, F(000)$ & 4 & 8 \\
\hline Dcalc, $\mathrm{Mgm}^{-3}$ & 1.258 & 1.428 \\
\hline$\mu, \mathrm{mm}-1$ & 0.959 & 1.688 \\
\hline$\theta \max , \operatorname{deg}$ & 30.56 & 25.25 \\
\hline no. refins collected & 33908 & 41345 \\
\hline no.reflns used & 14604 & 8164 \\
\hline no. of param. & 502 & 539 \\
\hline$R 1(\mathrm{~F})[\mathrm{F} 2>2 \sigma(\mathrm{F} 2)]^{[\mathrm{a}]}$ & 0.0786 & 0.0396 \\
\hline$w R 2(F 2)^{[\mathrm{b}]}$ (all data) & 0.2283 & 0.0794 \\
\hline $\mathrm{S}^{[\mathrm{c}]}$ (all data) & 1.016 & 0.986 \\
\hline
\end{tabular}

[a] $R_{1}(F)=\Sigma\left(\left|F_{o}\right|-\left|F_{c}\right|\right) / \Sigma\left|F_{o}\right|$ for the observed reflections $F^{2}>2 \sigma F$. [b] $w R\left(F^{2}\right)=\left\{\Sigma\left(F_{o}^{2}-F_{c}^{2}\right) / \Sigma w\left(F_{o}^{2}\right)^{2}\right\}^{1 / 2}$ [c] $S=\left\{\Sigma\left[\left(F_{o}^{2}-F_{c}^{2}\right)^{2}\right] /(n-p)\right\}^{1 / 2}, n=$ number of reflections, $p=$ number of parameters.

\section{Acknowledgements}

This work was supported by the Government of Spain (Project CTQ2012-30962), Junta de Andalucía (Project FQM6276), and European Union (FEDER funds). L. M. M. thanks a predoctoral research contract from Junta de Andalucía. We thank CESGA for granting access to computational resources (ICTS proposal no. 262).

Keywords: Alkoxide Complexes; Pincer Ligands; Alcohol Oxidation; Dehydrogenation; Reaction Mechanisms

[1] G. van Koten and D. Milstein in Organometallic Pincer Chemistry, Springer, Heidelberg, 2012

[2] a) K. J. Szabo and O. F. Wendt in Pincer and Pincer-Type Complexes. Applications in Organometallic Chemistry and Catalysis, Wiley,
Weinheim, 2014; b) D. Morales-Morales and C. G. M. Jensen in The Chemistry of Pincer Compounds, Elsevier, Amsterdam, 2007.

[3] a) J. I. van der Vlugt and J. N. H. Reek, Angew. Chem. Int. Ed. 2009 48, 8832-8846; b) J. I. van der Vlugt, Eur. J. Inorg. Chem. 2012, 363375 .

[4] a) N. Selander and K. J. Szabo, Chem. Rev. 2011, 111, 2048-2076; b) X. Hu, Chem. Sci. 2011, 2, 1867-1886.

[5] a) J. Cámpora, I. Matas, P. Palma, C. Graiff and A. Tiripicchio, Organometallics 2005, 24, 2827-2830; b) J. Cámpora, I. Matas, P. Palma, E. Álvarez, C. Graiff and A. Tiripicchio, Organometallics 2007 26, 5712-5721; c) J. Cámpora, I. Matas, P. Palma, E. Álvarez and C. Graiff, Organometallics 2007, 26, 3840.3849; d) I. Matas, J. Cámpora, P. Palma and E. Álvarez, Organometallics 2009, 28, 6515-6523.

[6] a) J. Cámpora, P. Palma, D. del Río and E. Álvarez, Organometallics 2004, 23, 1652-1655; b) J. Cámpora, P. Palma, D. del Río, M. M. Conejo and E. Álvarez, Organometallics 2004, 23, 5653-5655; c) L. M. Martínez-Prieto, C. Melero, D. del Río, P. Palma, J. Cámpora and E. Álvarez, Organometallics 2012, 31, 1425-1438; d) L. M. Martínez-Prieto, C. Real, E. Ávila, E. Álvarez, P. Palma and J. Cámpora, Eur J. Inorg. Chem. 2013, 5555-5566.

[7] C. Melero, L. M. Martínez-Prieto, P. Palma, D. del Río, E. Álvarez and J. Cámpora, Chem. Commun. 2010, 46, 8851-8853.

[8] a) N. T. S. Phan, M. Van der Sluys and C. W. Jones, Adv. Synth. Catal. 2006, 348, 609-679; b) E. Eberhard, Org. Lett. 2004, 6, 2125-2128; c) W. J. Sommer, K. Yu, J. S. Sears, Y. Ji, X. Zhang, R. J. Davis, D. Sherrill, C. W. Jones and M. Weck, Organometallics 2005, 24, 43514361.

[9] J. Choi, A. M. Roy McArthur, M. Brookhart and A. Goldman, Chem. Rev. 2011, 111, 1761-1779.

[10] D. Milstein, Top. Catal. 2010, 53, 915-923.

[11] a) G. Urgoitia, R. SanMartin, M. T. Herrero and E. Domínguez, Green Chem. 2011, 13, 2161-2166; b) O. Koise and S. Saito, Org. Biomol. Chem. 2010, 8, 896-900; c) C. Desmarets, S. Kuhl, R. Schneider and Y. Fort, Organometallics 2002, 21, 1554-1559; d) S. Kuhl, R. Schneider and Y. Fort, Adv. Synth. Catal. 2003, 345, 341-344.

[12] J. Breitenfeld, O. Vechorkin, C. Corminboeuf, R. Scopelliti and X. Hu, Organometallics 2010, 29, 3686-3689.

[13] a) S. Nückel and P. Burger, Organometallics 2001, 20, 4345-4359; b) C. M. Fafard and O. V. Ozerov, Inorg. Chim. Acta 2007, 360, 286-292.

[14] a) S. Chakraborty, J. A. Krause and H. Guan, Organometallics 2009, 28, 582-586; b) J. Breitenfeld, R. Scopelliti and X. Hu, Organometallics 2012, 31, 2128-2136.

[15] J. F. Hartwig, Organotranstion Metal Chemistry. From Bonding to Catalysis, University Science Books, Sausalito, California, 2010, pp. 398-405.

[16] a) O. Blum and D. Milstein, J. Am. Chem. Soc. 1995, 117, 4582-4594; b) J. Zhao, H. Hesslink and J. F. Hartwig, Organometallics 2001, 123, 7220-7227; c) S. A. Macgregor and P. Vadivelu, Organometallics 2007, 26, 3651-3659.

[17] a) H. E. Bryndza, J. C. Calabrese, M. Marsi, D. C. Roe, W. Tam and J. E. Bercaw, J. Am. Chem. Soc. 1986, 108, 4805-4813; b) S. M. Ng, C. Zhao and Z. Lin, J. Organomet. Chem. 2002, 662, 120-129.

[18] a) G.-J. ten Brink, I. W. C. E. Arends and R. A. Sheldon, Adv. Synth. Catal. 2002, 344, 355-369; b) G.-J. ten Brink, I. W. C. E. Arends, M. Hoogenraad, G. Verspui and R. A. Sheldon, Adv. Synth. Catal. 2003, 345, 1341-1352; c) M. J. Schultz, R. S. Adler, W. Zierkiewicz, T. Privalov and M. S. Sigman, J. Am. Chem. Soc. 2005, 127, 8499-8507; d) N. R. Conley, L. A. Labios, D. M. Pearson, C. C. L. McCrory and R. M. Waymouth, Organometallics 2007, 26, 5447-5453; e) R. M. Trend and B. M. Stoltz, J. Am. Chem. Soc. 2008, 130, 15957-15966; f) D. M. Pearson and R. M. Waymouth, Organometallics 2009, 28, 3896-3900.

[19] a) J. C. M. Ritter and R. G. Bergman, J. Am. Chem. Soc. 1998, 120, 6826-6827; b) O. Blum and D. Milstein, J. Organomet. Chem. 2000, 593-594, 479-484; c) N. A. Smythe, K. A. Grice, B. S. Williams and K. I. Goldberg, Organometallics 2009, 28, 277-288.

[20] a) G. R. Fulmer, R. P. Muller, R. A. Kemp and K. I. Goldberg, J. Am. Chem. Soc. 2009, 131, 1341-1347; b) G. R. Fulmer, A. N. Herndon, W. Kaminsky, R. A. Kemp and K. I. Goldberg, J. Am. Chem. Soc. 2011, 133, 17713-17726. 
[21] a) P. Kelley, S. Lin, G. Edouard, M. W. Day and T. Agapie, J. Am Chem. Soc. 2012, 134, 5480-5483; b) J. Cornella, E. Gómez-Bengoa and R. Martin, J. Am. Chem. Soc. 2013, 135, 1997-2009.

[22] M. Nielsen, A. Kammer, D. Cozzula, H. Junge, S. Gladiali and M. Beller, Angew. Chem. Int. Ed. 2011, 50, 9593-9597.

[23] a) K. R. Pörschke, Y. H. Tsay and C. Kruger, Inorg. Chem. 1986, 25, 2097-2099; b) L. C. Liang, Y. T. Hung, Y. L. Huang, P. S. Chen, P. Y. Lee and W. C. Chen, Organometallics 2012, 31, 700-708; c) R. Beck, M. Shoshani, J. Krasienkiewicz, J. A. Hatnean and S. A. Johnson, Dalton Trans. 2013, 42, 1461-1475.

[24] P. J. Dyson and J. S. Mclndoe, Transition Metal Carbonyl Cluster Chemistry, Gordon and Breach Science Publishers, Amsterdam, 2000, pp. 64-66.

[25] A. Moor, P. S. Pregosin, L. M. Venanzi and A. Welch, Inorg. Chim. Acta 1984, 85, 103-110

[26] a) C. Willocq, B. Tinant, F. Aubriet, V. Carré and S. Herrmans, Inorg Chim. Acta 2011, 373, 233-242; b) R. D. Feltham, G. Elbaze, C. Eck and J. Dubrawski, Inorg. Chem. 1985, 24, 1503-1510; c) E. G. Mednikov, N. K. Eremenko, Y. L. Slovokhotov and Y. T. Struchkov, Koord. Khim. 1987, 13, 979.

[27] M. Bochmann, I. Hawkins, L. J. Yellowless, M. B. Hursthouse and R. L. Short, Polyedron 1989, 8, 1351-1355

[28] a) B. N. Chaudret, D. J. Cole-Hamilton, R. S. Nohr and G. Wilkinson, J. Chem. Soc., Dalton Trans. 1977, 1546-1577; b) M. Portnoy, F. Frolow and D. Milstein, Organometallics 1991, 10, 3960-3962; c) D. MoralesMorales, R. Redón, Z. Wang, D. W. Lee, C. Yung, K. Magnuson and C. M. Jensen, Can J. Chem. 2001, 79, 823-829; d) M. B. Dinger and J. C. Mol, Organometallics 2003, 22, 1089-1095; e) S. M. Kloek, D. M. Heinekey and K. I. Goldberg, Organometallics 2006, 25, 3007-3011; f) N. J. Beach, J. A. M. Lummiss, J. M. Bates and D. E. Fogg, Organometallics 2012, 31, 2349-2356.

[29] a) N. Sieffert and M. Bühl, J. Am. Chem. Soc. 2010, 132, 8056-8070; b) N. Sieffert, R. Réocreux, P. Lorusso, D. J. Cole-Hamilton and M. Bühl, Chem. Eur. J. 2014, 20, 4141-4155.

[30] a) H. R. Gerberich and G. C. Seaman, Formaldehyde, in Kirk-Othmer Ecyclopedia of Chemical Technologies (Online). Vol. 1-22, Wiley, Updated by Staff 2013; b) W. Dankelman and J. H. M. Daemen, Anal. Chem. 1976, 48, 401-404.

[31] a) P. Kuzmic, DynaFit v. 4.05.103, BioKin Ltd., 2014; b) P. Kuzmik, Anal. Biochem. 1996, 237, 260-273.

[32] W. J. Hehre, A Guide to Molecular Mechanics and Quantum Chemical Calculations, Wavefunction, Inc., Irvine, California, 2003, p9. 357-374.

[33] a) J. Therjeiden, G. van Koten, I. C. Vinke, A. L. Spek. J. Am. Chem Soc. 1985, 107, 2891 -2898. b) M. Albrecht, A. L. Spek, G. van Koten, J. Am. Chem. Soc. 2001, 123, $7233-7246$.

[34] M. A. Ortuño, P. Vidossich, S. Conejero and A. Lledós, Angew. Chem. Int. Ed. 2014, 53, 14158-14161.

[35] a) T. Yamamoto, M. Abla and Y. Murakami, Bull. Chem. Soc. Japn 2002, 75, 1997-2009; b) T. Yamamoto and M. Abla, J. Organomet Chem. 1997, 535, 209-211; c) T. Yamamoto, A. Yamamoto and S. Ikeda, J. Am. Chem. Soc. 1971, 93, 3360-3364.

[36] a) R. H. Crabtree, The Organometallic Chemistry of Transition Metals, 3rd Ed., J. Wiley \& Sons, New York, 2001, p. 342; b) see Ref [15], p. 342.

[37] Spartan'14, Wavefunction, Inc., Irvine, CA.

[38] M. J. Frisch, et. al. Gaussian 09, Revision D.01, Gaussian, Inc., Wallingford, CT, 2010.

[39] A. W. Ehlers, et al., Chem. Phys. Lett. 1993, 208, 111-114.

[40] J. Tomasi, B. Manucci and R. Cammi, Chem. rev. 2005, 105, 29993093.

[41] SAINT, APEX2 Suite, v. 2.1, Bruker AXS Inc., Madison, Wisconsin, USA., 2006.

[42] G. Sheldrik, SADABS, APEX2 Suite, v. 2.1, Bruker AXS, Madison, Wisconsin, USA, 2006

[43] SIR-2002, APEX2 Suite, v. 2.1., Bruker AXS, Inc., Madison, Wisconsin USA., 2006.

[44] SHELXTL, v. 6.14, Bruker AXS, Inc., Madison, Wisconsin, USA, 20002003 


\section{FULL PAPER}

Stabilization of nickel or palladium methoxide complexes with PCP pincer ligands does supress $\beta$-hydrogen elimination.

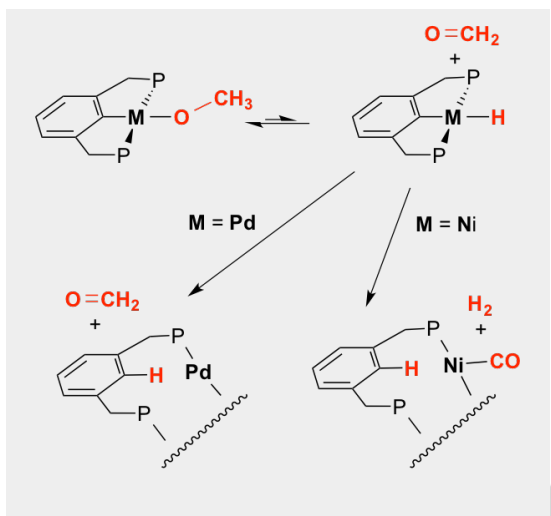

Luis M. Martínez-Prieto, Elena Ávila, Pilar Palma, Eleuterio Álvarez and Juan Cámpora*

\section{Page No. - Page No.}

$\beta$-Hydrogen Elimination Reactions of Nickel and Palladium Methoxides Stabilized by PCP Pincer Ligands 